Article

\title{
The Underlying Drivers of Underprivileged Households' Intention and Behavior towards Community Forestry Management: A Study Using Structural Equation Modelling and Artificial Neural Network Approach
}

\author{
Abdullah Al Mamun 1,*(D), Syed Ali Fazal ${ }^{2}\left(\mathbb{D}\right.$, Muhammad Mehedi Masud ${ }^{3}$, \\ Ganeshsree Selvachandran ${ }^{1}$, Noor Raihani Zainol ${ }^{4}$ and Quek Shio Gai ${ }^{1}$ \\ 1 Faculty of Business and Management, UCSI University, Cheras, Kuala Lumpur 56000, Malaysia; \\ ganeshsree@ucsiuniversity.edu.my (G.S.); queksg@ucsiuniversity.edu.my (Q.S.G.) \\ 2 College of Business Administration, International University of Business Agriculture and Technology, \\ Dhaka 1230, Bangladesh; fazal_cba@iubat.edu \\ 3 Faculty of Economics and Administration, University of Malaya, Kuala Lumpur 50603, Malaysia; \\ mehedi@um.edu.my \\ 4 Faculty of Entrepreneurship and Business, University Malaysia Kelantan, Pengkalan Chepa, \\ Kota Bharu 16100, Malaysia; raihani@umk.edu.my \\ * Correspondence: abdullaham@ucsiuniversity.edu.my; Tel.: +60-133003630
}

Received: 28 July 2020; Accepted: 5 September 2020; Published: 7 September 2020

\begin{abstract}
In acknowledging the significant role of forestry on the environmental, social, and economic sustainability of local communities, this study focused on examining how different factors affect the intentional behavior towards community forestry among the poor households in Malaysia. Employing theory of planned behavior (TPB) in an expanded model, this study collected data from 420 underprivileged households from 10 states in Malaysia using a survey questionnaire. Final analysis is performed using two methods, one being the well-established, conventional way of partial least square-structural equation modelling (PLS-SEM); the other being a frontier technology of computing using artificial neural network (ANN), which is generated through a deep learning algorithm to achieve the maximum possible accuracy for each of the five scenarios aforementioned. The study found that perceived benefits (PB) and eco-literacy (EL) have a significant positive effect on the attitude towards environment (ATE) while normative belief (NB) and motivation (MO) have a significant positive effect on subjective norms (SUN). Perceived control (PC) has a significant positive effect on perceived behavioral control (PBC). ATE, SUN, and PBC have a significant positive effect on the intention towards community forestry (ITCF), whereas the ITCF has a significant positive effect on community forestry adoption behavior (CFAB). When formulating and enforcing carbon reduction and poverty elevating programs through community forestry, the Malaysian government should consider the perceptions of poor families and the prerogative from their special reference groups to enhance the perceived ability of the vulnerable groups for positive and effective pro-environmental behavior that can lead to sustainable forestry management.
\end{abstract}

Keywords: community forestry; theory of planned behavior; low-income; Malaysia

\section{Introduction}

Environmental degradation in terms of large volumes of unhealthy emissions (e.g., $\mathrm{CO}_{2}$ ) causing global warming, greenhouse effect, acid rain, and other climate-change-related pollutions have raised 
people's consciousness on environmental awareness and green lifestyle; wherein uncertainties regarding future access to fossil fuels along with the significant volume of carbon emissions being produced have been widely recognized as the current millennium's largest challenges [1]. It is believed that sustainable development can preserve the degrading environmental, social, and economic aspects associated with the human's life. The issue is more relevant to emerging economies such as Malaysia, where rapid unsustainable growth can result in significant income inequalities along with socioeconomic and environmental vulnerabilities that continue to threaten the wellbeing of low-income communities in the country [2]. Sustainable development is found to prioritize the environmental (planet) dimension than its social (people) and economic (profit) pillars through concepts such as zero-growth, de-growth, and ecological economics [3]. By adopting the sustainable development goals, the world's development agenda for future has shifted towards the ecological sustainability dimension, which is firmly integrated into development and poverty alleviating efforts [3]. In this context, sustainable forest management and participatory forestry are recognized as an effective approach to achieve ecological sustainability that significantly contributes towards sustainable development [4].

Afforestation and sustainable forest development are thus significant to achieve community-based socioeconomic development, maintain the sustainability of forest ecosystems, and address global warming through carbon reduction [5,6]. According to Sharma [7], forests are generally important in the 21st century because they help mitigate climate change, foster biodiversity, and provide natural resources for economic development. In a more recent study Njurumana, Ginoga, and Octavia [8] noted synergizing the ecological, socio-economic, and community livelihood benefits as one of the goals of managing global forest ecosystems today. Specifically, forestry remains significant for rural communities across the world, who depend on forests for their livelihoods and subsistence [7]. Perhaps it is why enhancing forests based on social, economic, and environmental parameters, along with uplifting livelihoods of people who depend on forests, is one of the Global Forest Goals [9]; credit goes to the ability of forests to provide livelihoods to poor communities who depend on forests for the availability of material resources for their daily needs, including animal feed, food, energy, water, spirituality and health, as well as source of income; thereby playing crucial role in reducing poverty [8]. Several governments currently encourage the development of the forestry sector as one of the solutions to alleviate poverty in communities surrounding the forest through social forestry policies and forest area utilization schemes $[10,11]$, one of which is community forestry that aims to provide space for participation of the community in managing forests [8].

In the United Kingdom, community forestry projects reflect a diverse range of social activities that are associated with the management and the use of forestry resources. These activities have achieved successful rural empowerment levels by bringing sustainable income and livelihood to local communities that are involved in decision making, leadership, and management of the forestry resources, thereby gaining benefits from them [12]. Community-based forestry is perceived to conserve not only forest ecosystems, but also improve the social status, wellbeing, and recognition of rural poor communities that depend on them, thereby promoting sustainable community development $[12,13]$. According to Abdullah et al. [13], people-oriented participatory forest development programs that are adopted in Bangladesh, India, Vietnam, Nepal, Thailand, and the Philippines are considered effective strategies for sustainable socioeconomic development for local communities. The strategies can positively and substantially affect the lifestyle, income, and living standards of participating individuals. In Malaysia, it is believed that participatory or community forestry can catalyze socio-economic changes leading to ecological integrity while providing the subsistence needs of locals simultaneously [14].

It can be said that forest sustainability impacts the local communities as its development must accommodate the desires of the community members. According to Nelson, Muhammed, and Rashid [15], forests and local communities enjoy a mutual relationship wherein forestry contribute significantly to the management of community's livelihood and sustainability. On the other hand, poverty-driven communities around forest areas contribute directly towards increased deforestation [8]. Thus, the local community's perception and participation are essential to address social, economic, and 
environmental issues as well as ensuring sustainable development through community forestry $[5,6]$. Nelson et al. [15] highlighted that there is the need to study the contingencies between communities and forestry. In Malaysia, it is known that poor engagement of local communal groups in the management and establishment of protected areas have caused unfavorable behaviors towards sustainable utilization of natural resources [16].

It is evident that environmental concerns represent burning issues; for governments, societies, and business organizations [1], which call for immediate research attention into sustainable forest development that have the potential to achieve community-based socioeconomic development, maintain the sustainability of forest ecosystems, foster biodiversity, address global warming through carbon reduction, and mitigate other climate challenges [5-7]. Moreover, Malaysia needs a framework for sustainable community forestry that can engage all stakeholders in the local communities to establish common grounds for sustainable forest management and sustainable development [14,15], which further necessitate this study. Furthermore, many of the concerned communities are constantly experiencing socio-economic limitations, which could improve through their participation in community forestry programs [8]. Interestingly, studies portraying the socio-economic benefits of forestry supporting community livelihoods do exist, however the information on the drivers of such communities towards community forestry management remains unexplored. Hence, we intended to examine the factors affecting the intentional behavior towards community forestry among the underprivileged head of household in Malaysia using an extended theory of planned behavior (TPB) model. It is hoped that this study could address the gaps and extend the limited literature on intentional behavior of large communal groups towards community-based forestry and forward relevant policy recommendations for practical implication.

\section{Literature Review}

\subsection{Theory of Planned Behavior (TPB)}

The success or effectiveness of a specific behavior, including community forestry, is contingent on how it is perceived by individuals and their surrounding society [17]. Therefore, this research applied TPB to understand the relationships between the attitude of local public towards environment (ATE), SUN, perceived behavioral control (PBC), behavioral intentions towards community forestry (ITCF), and adoption behavior towards community forestry (CFAB). It is believed that this link is missing in the existing literature. TPB depicts that human behavior is influenced by behavioral intentions, which is collectively set by behavioral beliefs (BB), normative beliefs (NB), and control beliefs (CB) [18]. BBs are the product of particular BBs and the outcome evaluations that can construct an individual's attitude towards specific behavior; $\mathrm{NB}$, and the MO to comply correlate to an individual's SUN, whereas control beliefs and control strength form an individual's PBC $[5,18,19]$. This study reviewed studies that employed TPB to investigate forestry-related intentions and adoption behaviors in determining the dimensions that can be used to capture specific ATE $[5,19]$.

In general, TPB initiates the environmental knowledge, attitudes, and societal values to reveal how the psychological traits of household's decision making along with the behavior-modification processes can stimulate environmentally responsible behavioral patterns [20]. Related studies suggested that environmental knowledge, concern, awareness of benefits, and emotions can determine environment-specific attitudes; normative values and MO are associated with SUN; along with PC in determining PBC are linked to each other and collectively influenced pro-environmental intention and behavior [20-26].

Based on the above, we finalized the research model for this study. TPB depicts that BBs are the product of particular BBs and the outcome evaluations construct an individual's attitude towards specific behavior; hence, following Ajzen [18] and others [5,17,19-21,26,27] this study integrated the $P B$ and EL as the dimensions for low-income head of household's ATE. Similarly, as NB, and the MO to comply determine an individual's SUN, we followed Ajzen [18] and related studies [19-21,24,27,28] 
to hypothesize $N B$ and $M O$ as determinants of SUN. Finally, control beliefs and control strength are known to form an individual's PBC; therefore, we proposed the construct of $P C$ as the predictor of PBC [18-20,26,27]. Thus, we used the described extended TPB model to examine the intention and behavior towards community forestry among the underprivileged households in Malaysia through the various hypotheses, as outlines below.

\subsection{Attitude towards Environment}

In the present context, attitudes can be defined as the overall attitude or beliefs of the low-income households towards the environment and evaluation of outcomes associated with pro-environmental behavior (e.g., community forestry). It is expected that individuals with positive environmental attitude are less likely to evade their responsibility in conserving their surrounding environment [20,29]. Theoretically, TPB denotes that the more favorable an individual's attitude towards a certain behavior, it is more likely that the individual will act positively towards the object [18]. In a related study, Calkins and Thant [20] confirmed the link between individual's attitudes and green behaviors. According to Foundjem-Tita et al. [17], an individual's attitude can be a suitable approximation to determine intention, particularly a pro-environmental behavior such as planting trees. Moreover, Lin et al. [5] reported that favorable attitude towards carbon reduction and afforestation could increase the individuals' intention to engage in such programs. Relying on theory [18] and related literature [19,23,25-27], this study affirmed that positive attitudes towards the environment among the underprivileged households in Malaysia could be one of the factors that may positively affect their ITCF.

\subsection{Perceived Benefits}

Following $\mathrm{Wu}$ and Chen [27], this study defined perceived benefit as individual perception of functionality and quality of environmentally friendly behavior and the anticipation of one's expectations being met by such behavior. An individual attitude is made up of beliefs regarding a particular behavior and the calculations regarding their outcomes $[5,19]$. In general, awareness about the environment and its self-expressive benefits are known to positively affect attitude, which in turn positively impact behavioral intention [21]. Hartmann and Apaolaza-Ibáñez [24] further extended that psychological brand benefits can significantly enhance individuals' attitudes towards a green lifestyle. Karppinen [19] highlighted that pro-environmental behavior such as reforestation is associated with positive beliefs that form favorable attitudes among individuals. According to Foundjem-Tita et al. [17], individuals' pro-environmental behavior such as tree planting is dependent on the perception of benefits associated with the activity. It is important to determine the benefits of pro-environmentalism among the underprivileged households in Malaysia in developing a positive attitude towards community forestry.

\subsection{Eco-Literacy}

Environmental knowledge or EL refers to the concepts of general understanding of environmental issues, as well as awareness of connection between eco-friendly behavior and sustainable development, which is one of the imperative elements that affect pro-environmental behavior [26]. If individuals lack the environmental knowledge, it can create an attitude-behavioral gap between the concern for environmental and actual pro-environmental behavior. On the other hand, individuals with knowledge about environmental issues can adopt a favorable attitude towards an environmentally friendly lifestyle. Existing empirical evidence revealed that environmental knowledge or EL is the principal factor that has an indirect effect on green behavior through individuals' attitude [21,26]. It is argued that households endowed with adequate task knowledge and environmental information should adopt a positive environmental attitude and make appropriate choices [20]. 


\subsection{The Mediating Role of Attitude towards Environment}

This study hypothesized a direct positive effect of PB and EL on ATE as well as a direct positive effect of ATE on the ITCF. This study assumed that there is a mediating interference of ATE on the relationships of $\mathrm{PB}$ and EL with the ITCF among the underprivileged households in Malaysia. Existing literature supported that PB and EL can serve as an indirect measurement of ITCF via the concept of ATE $[5,19,27]$. Empirical evidence confirmed that constructs such as EL and PB could have a distinct indirect effect on green intention behavior through individuals' attitude $[21,24,26]$.

\subsection{Subjective Norms}

SUN could be perceived as the impact of views of significant reference groups in the form of opinions that influence one's decision to perform or not to perform a specific behavior $[18,26]$. The success or effectiveness of a specific behavior such as community forestry is contingent on how it is perceived by individuals, which is influenced by the surrounding society. Lin et al. [5] found that significant others have a greater effect on people who have a positive attitude towards afforestation, and they are willing to engage in forestry-related actions. A recent study by Maichum et al. [26] confirmed that SUN have a significant positive effect on pro-environmental intention such as the purchase of green products. Relying on theory [18] and related literature [23,25-27], this study affirmed that positive SUN among the underprivileged groups in Malaysia is one of the factors that may positively affect the ITCF.

\subsection{Normative Beliefs}

NB can be defined as an individual's perceptions of the degree he or she should yield to social pressure [27]. NB refer to the perception of the significant others or specific groups about the individuals in performing or not performing community forestry. SUN are known to be preceded by NB [18]. A study by Karppinen [19] confirmed that normative pressures could affect the intention towards natural reforestation. In an earlier study, $\mathrm{Wu}$ and Chen [27] suggested that a significant degree of confidence in social norms generally can guarantee individual behavior by specific social expectations; thus, NB could become an important determinant of individual's behavior through SUN.

\subsection{Motivation}

$\mathrm{MO}$ in the present context refers to individuals' MO to comply with significant specific referents in performing or not performing community forestry. Common classical pro-social behavioral theory highlights that MO facilitates individuals to contribute towards a common good [24], which could be forestry-related activities. Moreover, SUN are known to be predicted by the MO of individuals to comply with specific significant referents [19]. Calkins and Thant [20] suggested that MOal factor among individuals is a crucial ingredient for behavioral alteration because it stimulates the obligation towards society. Regarding the pro-environmental behavior, the literature further conveyed that $\mathrm{MO}$ such as higher social status, reputation, or psychological motive can lead individuals to choose green lifestyle over non-green alternatives [21,24,28].

\subsection{The Mediating Role of SUN}

This study hypothesized a direct positive effect of NB and MO on SUN as well as a direct positive effect of SUN on ITCF. It is expected that there is a mediating interference of SUN on the associations of NB and MO with ITCF among the underprivileged households in Malaysia. Moreover, SUN is determined by a NB coupled with the MO to comply; both NB and MO can be expected to influence the ITCF through natural regeneration $[5,19]$. In other words, NB and MO can serve as an indirect measurement of ITCF via the concepts of SUN. 


\subsection{Perceived Behavioral Control}

According to Ajzen [18], PBC in the present context can be defined as the subjective judgments of low-income households over the capability and availability of necessary resources relevant to perform community forestry. The actors' willingness to perform a specific behavior is significantly predicted by the extent of PBC that reflects the ability to control difficulties associated with such behavior [5]. Thus, individuals with better means to engage in afforestation are more willing to participate in related activities [5]. TPB asserts that forming PBC is essential for generating behavioral intention. Maichum et al. [26] confirmed that PBC has influence on pro-environmental plan such as the purchase of environmentally friendly products. Several types of behaviors cannot be expected to be dependent solely on individual's volitional control [19]. Based on theory [18] and related literature [25,27], this study affirmed that positive PBC of poor households in Malaysia is necessary to influence the ITCF positively.

\subsection{Perceived Control}

TPB asserts that PBC comprised of control belief and control strength $[18,19]$. The construct of PC reflects the control beliefs that can influence an individual's PBC, thereby facilitating or inhibiting a person in performing a certain behavior $[19,27]$ such as community forestry. The control beliefs, in accordance with the TPB, describe the perceived difficulty or ease of performing a specific behavior as evaluated by the actors [18]. Calkins and Thant [20] stated that households with a stronger feeling of effectiveness or PC could significantly undertake more environmentally responsible actions. In an earlier study, Karppinen [19] confirmed that control factors could affect the intention towards natural reforestation. Moreover, Maichum et al. [26] mentioned that control factors such as self-efficacy, convenience, and availability are the most important factors to influence individuals' pro-environmental behavior.

\subsection{The Mediating Role of $P B C$}

This study hypothesized a direct positive effect of PC on PBC as well as a direct positive effect of PBC on the ITCF. Therefore, a significant mediating effect of PBC is expected in the relationship between PC and the ITCF among the underprivileged households in Malaysia. Moreover, PC can be expected to influence ITCF through natural regeneration because PBC is determined by control beliefs $[5,19]$. It can be said that PC can serve as an indirect measurement of ITCF via the concept of PBC.

\subsection{Intention towards Community Forestry}

Behavioral intention is considered a measure of the degree or willingness to which an individual is likely to perform certain behavior [18]. On the other hand, actual behavior is the dynamic process involving interactions between mental, emotional, and materialistic fields that can result in a specific set of activities performed by individuals to satisfy their needs [27]. This study concurred with the definition of pro-environmental behavior as the activities performed intentionally to diminish the negative influence on the surrounding environment [29]. TPB supports behavioral intention as the most immediate determinant of actual behavior [18]. It is believed that intentions can explain the significant proportions in the variance of actual behavior [20]. According to the existing empirical evidence, intention is the main and most suited determinant, which significantly and positively predicts actual human behavior in pro-environmental activities [26,27].

\subsection{The Mediating Role of ITCF}

This study hypothesized a direct positive influence of ATE, SUN, and PBC on the ITCF. There is also a direct positive effect of intention towards community forest on community forestry adoption behavior (CFAB). Therefore, it is expected that there is a significant mediating effect of ITCF between 
ATE, SUN, and PBC on CFAB. TPB stated that actual behavior is preceded by behavioral intention, which is induced by specific attitude, subjective norm, and PBC [18]. It is expected that attitude towards specific behavior along with SUN and PBC can affect the adoption behavior towards community forestry by natural regeneration through behavioral intentions [26].

\section{Methods}

This study has collected data via structured interviews to measure the effect of selected variables on the intention and behavior towards community foresting among poor households in the rural areas. Based on information from The Implementation and Coordination Unit of the Prime Minister's Department (ICU-JPM), Malaysia, this study defined low-income or underprivileged households as families from Coastal Peninsular Malaysia with a net income below RM2000 [30]. This study obtained the database of Malaysian low-income households with specific details including name, address, and contact details from selected Financial Institutions such as Majlis Amanah Rakyat (2690 Households), Majlis Agama Islam dan Adat Istiadat Melayu Kelantan (150 Households), Amanah Ikhtiar Malaysia (158 Households), and e-Kasih under the Implementation and Coordination Unit of the Prime Minister's Department (519 Households) Malaysia.

The team that managed data collection has contacted the selected leader of households to explain the survey's reason or purpose and arranged the appointments for interview before continuing with the fieldwork. The data collection was completed in December 2017 and the beginning of January 2018, from 420 respondents via structured interview. Altogether, the following are the distribution of the respondents: (1) 170 under MARA (120 from Tumpat and 50 from Bachok) and 40 under MAIK in Kelantan ( 25 from Pasir Mas, 5 from Tanah Merah, 5 from Kuala Krai, and 5 from Pasir Puteh); (2) 105 from Kedah (3 from Kulim, 10 from Baling; 20 from Kuala Muda, 6 from Yan, 11 from Sik, 11 from Kubang Pasu, 7 from Pokok Sena, 24 from Kota Setar; 7 from Padang Terap, 3 from Pendang; and 3 from Bandar Baharu); and (3) 105 from Terengganu (8 from Kuala Terengganu 143 from Kuala Terengganu 222 from Hulu Terengganu, 16 from Dungun, and 16 from Kemaman).

\subsection{Sample Size}

Using G-Power version 3.1, sample size was estimated. Considering the effect size of 0.15 and power of 0.95 , the required sample size is 166 , confirming the research model with nine predictors [31]. Apart from G-Power, this study consulted Wolf, Harrington, Clark, and Miller [32], who noted that the sample size for structural equation modeling could be between 30 and 450. Moreover, Reinartz, Haenlein, and Henseler [33] recommended a minimum sample size of 100. However, to avoid complication related to small sample size, this study collected data from 420 respondents across all coastal states of Malaysia, which portrays statistically adequacy and representative sampling.

\subsection{Research Instrument}

Questionnaire was main research instrument, which was developed considering simple unbiased wordings and perceptual measures that could facilitate respondents to comprehend the items easily. The items for EL are selected from Maichum et al. [26] and Mostafa [34]. The questions for the ATE are selected from Ha and Janda [23] and Maichum et al. [26], perceived benefit and SUN from Wu and Chen [27] and Maichum et al. [26], and perceived behavior control from Maichum et al. [26]. Lastly, the items used to measure the intentions towards community forestry were adopted from Chen and Deng [35] and Maichum et al. [26] and the questions for CFAB are selected from Walton and Austin [36], Sánchez, et al. [37], and Osman, et al. [38]. A seven-point Likert scale was used for the dependent variables, whereas a five-point Likert scale was employed to capture all independent variables.

\subsection{Common Method Variance (CMV)}

Following Podsakoff et al. [39], this study used "seven-point Likert scale" for the dependent variables and "five-point Likert scale" for all independent variables as the procedural remedy. Moreover, 
this study used Harman's one-factor test as the statistical remedy [39]. The results revealed that one component described $33.12 \%$ of the variance, that is below the maximum threshold of $50 \%$. In addition, the correlation coefficient $<0.9$ between constructs is considered an indicator of CMV [40]. None of the correlation coefficients do not exceed the threshold value of 0.90 that witnessed the lack of common method bias in the dataset.

\subsection{Multivariate Normality}

Web Power online tool is applied to test multivariate normality. The result shows that the $p$-values of both kurtosis and Mardia's multivariate skewness are $>0.05$, which confirms multivariate non-normality in the dataset.

\subsection{Analysis Method}

Due to the non-normality issue and exploratory in nature, this study employed the PLS-SEM [41] estimation with the purpose of maximizing the explanation of variance in the structural equation model for dependent constructs [42]. The findings of the analysis are in accordance with the suggestions of Hair et al. [42] for PLS-SEM modelling. On the other hand, considering the recent advancements in computing, this study also deploys a frontier technology of computation: Artificial neural network (ANN), which is to be constructed through a deep learning algorithm rather than by human input. In fact, ANN is based on the replication of the biological nerve cell of the human brain. To accomplish the computation, this study chooses ANN with two stages. SEM rely on predetermined linkages between the input and the output variables by the user. This present a significant risk as the user will very potentially oversimplify the relationship by declaring himself that certain linkages do not exist between 2 variables that are actually related, which the user does not realize. Moreover, SEM only consider the linear relationships between the input and the outputs, which has an extremely high risk of oversimplifying real-life situations as many correlations in real life are non-linear in nature [43]. On top of these, the weightage in SEM are restricted to real value within 0 and 1 , and the input variables are by default dependent on one another, where an increase in an input variable must be compensated by the decrease in another input variable in an SEM model.

ANN on the other hand is in contrast to SEM, where all the inputs are assumed by default to have a connection with all the intermediate nodes, and all the intermediate nodes in turn are assumed by default to have a connection with all the outputs as well. In particular, the connection between each input $x_{i}$ with each intermediate node $o_{k}$ is characterized by a parameter $w_{i, k}$, and likewise, the connection between each intermediate node $o_{k}$ with each output $y_{j}$ is characterized by a parameter $v_{k, j}$ as portrayed in the figure above.

In such a system of ANN, all $x_{i}, o_{k}$, and $y_{j}$ are collectively referred as nodes, each of them is analogous to the body of a biological nerve cell in human brain. On the other hand, each $w_{i, k}$ and $v_{k, j}$ is analogous to a connection between two biological nerve cells in human brain. Such $w_{i, k}$ and $v_{k, j}$ are thus collectively called synaptic weights. Moreover, in analogy to the growth of a human brain, all $w_{i, k}$ and $v_{k, j}$ start with a uniform value, which then increase or decrease in magnitude as the ANN learns about the raw data.

Hence, all intermediate nodes $o_{k}$ are related to the input nodes $x_{i}$ by the following formula.

$$
o_{k}=\sum_{\alpha=1}^{n} w_{\alpha, k} x_{\alpha} \text { for all } k=1,2, \ldots, m
$$

In turn, all the output nodes $y_{j}$ are related to the intermediate nodes $o_{k}$ by the following formula.

$$
y_{j}=\operatorname{round}\left(\sum_{\alpha=1}^{m} v_{\alpha, j} o_{\alpha}\right) \text { for all } j=1,2, \ldots, p
$$


where round $(x)$ denotes the rounding up of $x$ to the nearest integer. This is in conjunction with the nature of the true value, which is an integer among $1,2,3 \ldots 7$.

In both the 2 cases above, all the synaptic weights $w_{i, k}$ and $v_{k, j}$ are thus to be deduced by the AI, such that the output from the ANN:

$$
y_{1}, y_{2}, \ldots, y_{p}
$$

are the most accurate predictions to the true values

$$
t_{1}, t_{2}, \ldots, t_{p}
$$

Across all, input the pattern $v \in N$ given in the dataset.

Such accuracy is in turn measured through two (2) different formula as highlighted below:

Sum of squared estimate of errors (SSE):

$$
\operatorname{SSE}=\sum_{v \in N} \sum_{j=1}^{p}\left(y(v)_{j}-t(v)_{j}\right)^{2}
$$

Root mean square error (RMSE)

$$
\text { RMSE }=\sqrt{\frac{1}{p|N|} \sum_{v \in N} \sum_{j=1}^{p}\left(y(v)_{j}-t(v)_{j}\right)^{2}}
$$

Moreover, the average synaptic weight will also be calculated alongside for a group of data.

The procedure above is conducted for the following 5 scenarios as discussed below:

First Scenario: Prediction of the ATE based on PB and EL. In this scenario, the ATE is reflected by the following 6 feedbacks from the questionnaire:

1. "Environmental protection is important to you when making purchase decision." (notation: $A_{1}$ )

2. "Between environmentally friendly and conventional products, you prefer environmentally friendly one." (notation: $A_{2}$ )

3. "Practicing environmentally friendly lifestyle is necessary to mitigate global warming." (notation: $A_{3}$ )

4. "You think environmentally friendly lifestyle is crucial for the future of our existence." (notation: $A_{4}$ )

5. "You think that environment friendly business is a good idea." (notation: $A_{5}$ )

6. "You think that environment friendly consumptions are safe." (notation: $A_{6}$ )

Each can take an integer value ranged from 1 to 7 .

On the other hand, PB is reflected by the following 6 feedbacks from the questionnaire:

1. "Environmentally friendly lifestyle may lead to new and better ways to clean up the environmental hazards." (notation: $P_{1}$ )

2. "Environmentally friendly lifestyle may help us to innovate sustainable and eco-friendly ways to deal with environmental issues." (notation: $P_{2}$ )

3. "Environmentally friendly lifestyle may lead to new and better ways to treat and solve social problems." (notation: $P_{3}$ )

4. "Environmentally friendly lifestyle is safe for everyone and everything around us." (notation: $P_{4}$ )

5. "Environmentally friendly lifestyle does not harm our society including animals and plants." (notation: $P_{5}$ )

6. "There is no significant risk associated with environmentally friendly lifestyle." (notation: $P_{6}$ )

Meanwhile, EL is reflected by the following 6 feedbacks from the questionnaire:

1. "You prefer to check the eco-labels and certifications on products before purchase." (notation: $E_{1}$ ) 
2. "You want to have a deeper insight of the inputs, processes and impacts of green products." (notation: $E_{2}$ )

3. "You would prefer to gain substantial information on green products before purchase." (notation: $E_{3}$ )

4. "Your knowledge helps to buy products and packages that are environmentally safe." (notation: $E_{4}$ )

5. "You know how to select products and packages that reduce the amount of waste ending up in landfills." (notation: $E_{5}$ )

6. "You understand the environmental phrases and symbols on product package." (notation: $E_{6}$ )

Likewise, all of these feedback takes an integer value ranged from 1 to 7 .

The information for each of the feedback needs to be preserved for every factor on concern. For instance, scoring 4 on $P_{1}$ and 2 on $P_{2}$, will have the two numbers add up to 6, but must be regarded as a distinct entity from scoring 3 on both $P_{1}$ and $P_{2}$, even if those latter numbers add up to 6 as well.

Therefore, take $\mathbf{A}=\left(A_{1} A_{2} A_{3} A_{4} A_{5} A_{6}\right)$ representing all the feedbacks cornering ATE. Likewise, take $\mathbf{P}=\left(P_{1} P_{2} P_{3} P_{4} P_{5} P_{6}\right)$ and $\mathbf{E}=\left(E_{1} E_{2} E_{3} E_{4} E_{5} E_{6}\right)$, which represent all the feedbacks concerning $\mathrm{PB}$ and EL respectively.

Our aim in this scenario is thus to generate the best two stage ANN to predict $\mathbf{A}$ from $\mathbf{P}$ and $\mathbf{E}$, using our deep learning algorithm. There will be one extra input node that is always taken to be the constant 1 .

Hence, there will be altogether 13 input nodes, $x_{1}$ to $x_{13}$; and 6 output nodes, $y_{1}$ to $y_{6}$. Considering the caliber of our workstations, the number of intermediate nodes is chosen to be the same as the number of output nodes, hence $o_{1}$ to $o_{6}$.

Second Scenario: Prediction of the SUN based on NB and MO.

In this scenario, $\mathrm{SUN}$ is reflected by the following 5 feedbacks from the questionnaire:

1. "You feel under social pressure to practice environmentally friendly lifestyle." (notation: $S_{1}$ )

2. "You feel bad if you choose to buy conventional products instead of environmentally friendly products." (notation: $S_{2}$ )

3. "Everyone has a responsibility to contribute to environmental preservation by purchasing environmentally friendly products." (notation: $S_{3}$ )

4. "Everyone has a responsibility to promote environmentally friendly behavior among others." (notation: $S_{4}$ )

5. "Most people who are important to you would wish you to practice environmentally friendly lifestyle." (notation: $S_{5}$ )

Each can take an integer value ranged from 1 to 7 .

On the other hand, NB is reflected by the following 6 feedbacks from the questionnaire:

1. "Your family think you should practice environmentally friendly behavior." (notation: $N_{1}$ )

2. "Your friends think you should practice environmentally friendly behavior." (notation: $N_{2}$ )

3. "You value the opinion and feeling of your family on your environmentally friendly behavior." (notation: $N_{3}$ )

4. "You value the opinion and feeling of your friends on your environmentally friendly behavior." (notation: $N_{4}$ )

5. "Your family think you should consume environment friendly products." (notation: $N_{5}$ )

6. "Your friends think you should consume environment friendly products." (notation: $N_{6}$ ) 
Where as MO is reflected by the following 6 feedbacks from the questionnaire:

1. "You are motivated to practice environmentally friendly lifestyle." (notation: $M_{1}$ )

2. "Your personal philosophy is to do anything to practice environmentally friendly lifestyle." (notation: $M_{2}$ )

3. "You want to promote the environmentally friendly lifestyle among others." (notation: $M_{3}$ )

4. "You are able to use your past experience and training to practice environmentally friendly lifestyle." (notation: $M_{4}$ )

5. "You want to prove that you can practice environmentally friendly lifestyle." (notation: $M_{5}$ )

6. "You want to contribute to the world by practicing environmentally friendly lifestyle." (notation: $M_{6}$ )

7. "You want to have a career focused on solving environmental issues." (notation: $M_{7}$ )

Likewise, all of these feedback takes an integer value ranged from 1 to 7.

As the information for each feedback needs to be preserved as well, take $\mathbf{S}=\left(S_{1} S_{2} S_{3} S_{4} S_{5}\right)$ representing all the feedbacks cornering SUN. Likewise, take $\mathbf{N}=\left(N_{1} N_{2} N_{3} N_{4} N_{5} N_{6}\right)$ and $\mathbf{M}=\left(M_{1} M_{2} M_{3} M_{4} M_{5} M_{6} M_{7}\right)$ which represent all the feedbacks concerning $\mathrm{NB}$ and MO respectively.

Our aim in this scenario is thus to generate the best two stage ANN to predict $\mathbf{S}$ from $\mathbf{N}$ and $\mathbf{M}$, using our deep learning algorithm. There will be one extra input node that is always taken to be the constant 1 .

Hence, there will be altogether 14 input nodes, to $x_{14}$; and 5 output nodes, $y_{1}$ to $y_{5}$. Considering the caliber of our workstations, the number of intermediate nodes is chosen to be the same as the number of output nodes, hence $o_{1}$ to $o_{5}$.

Third Scenario: Prediction of the perceived behavioral control (PBC) based on PC.

In this scenario, $\mathrm{PBC}$ is reflected by the following 7 feedbacks from the questionnaire:

1. "You are confident that you can practice environmentally friendly lifestyle." (notation: $Q_{1}$ )

2. "You see yourself as capable of practicing environmentally friendly lifestyle." (notation: $Q_{2}$ )

3. "You have resources to practice environmentally friendly lifestyle." (notation: $Q_{3}$ )

4. "You have time to search and practice environmentally friendly lifestyle." (notation: $Q_{4}$ )

5. "You have willingness to practice environmentally friendly lifestyle." (notation: $Q_{5}$ )

6. "There are likely to be plenty of opportunities for you to practice environmentally friendly lifestyle." (notation: $Q_{6}$ )

7. "Being environmentally friendly would be entirely within your control." (notation: $Q_{7}$ )

Each can take an integer value ranged from 1 to 7 .

On the other hand, PC is reflected by the following 6 feedbacks from the questionnaire:

1. "Practicing environmentally friendly lifestyle is not so expensive." (notation: $R_{1}$ )

2. "Finding environmentally friendly products or services do not take much time and effort." (notation: $R_{2}$ )

3. "Location of environmentally friendly products or services is convenient." (notation: $R_{3}$ )

4. "Buying environmentally friendly products is possible as they are available in my areas." (notation: $R_{4}$ )

5. "Buying environmentally friendly products is possible as they are easy to identify." (notation: $R_{5}$ )

6. "You have enough money to buy environmentally friendly products." (notation: $R_{6}$ ) 
Likewise, all of these feedback takes an integer value ranged from 1 to 7.

As the information for each feedback needs to be preserved as well, take $\mathbf{Q}=\left(Q_{1} Q_{2} Q_{3} Q_{4} Q_{5} Q_{6} Q_{7}\right)$ representing all the feedbacks cornering PBC. Likewise, take $\mathbf{R}=\left(R_{1} R_{2} R_{3} R_{4} R_{5} R_{6}\right)$, which represent all the feedbacks concerning PC.

Our aim in this scenario is thus to generate the best two stage ANN to predict $\mathbf{Q}$ from $\mathbf{R}$, using our deep learning algorithm. There will be one extra input node that is always taken to be the constant.

Hence, there will be altogether 7 input nodes, $x_{1}$ to $x_{7}$; and 7 output nodes, $y_{1}$ to $y_{7}$. Considering the caliber of our workstations, the number of intermediate nodes is chosen to be the same as the number of output nodes, hence $o_{1}$ to $o_{7}$.

Forth Scenario: Prediction of the ITCF based on ATE, SUN, and perceived behavioral control (PBC). In this scenario, ITCF is reflected by the following 7 feedbacks from the questionnaire:

1. "You would star community foresting even if the outcome is uncertain." (notation: $I_{1}$ )

2. "The probability that you will start community foresting is very high." (notation: $I_{2}$ )

3. "You plan to start foresting rather than de-foresting." (notation: $I_{3}$ )

4. "You will consider community foresting for ecological reasons." (notation: $I_{4}$ )

5. "You intend to start community foresting." (notation: $I_{5}$ )

6. "If you have an opportunity, you will consider community foresting." (notation: $I_{6}$ )

7. "If you have an opportunity, you will consider foresting for ecological reasons." (notation: $I_{7}$ )

Each can take an integer value ranged from 1 to 7 .

As the information for each feedback needs to be preserved as well, take $\mathbf{I}=\left(\begin{array}{lllllll}I_{1} & I_{2} & I_{3} & I_{4} & I_{5} & I_{6} & I_{7}\end{array}\right)$, which represent all the feedbacks concerning ITCF.

Our aim in this scenario is thus to generate the best two stage ANN to predict I from A (see scenario 1), $\mathbf{S}$ (see scenario 2), and $\mathbf{Q}$ (see scenario 3), using our deep learning algorithm. There will be one extra input node that is always taken to be the constant 1 .

Hence, there will be altogether 19 input nodes, $x_{1}$ to $x_{19}$; and 7 output nodes, $y_{1}$ to $y_{7}$. Considering the caliber of our workstations, the number of intermediate nodes is chosen to be the same as the number of output nodes, hence $o_{1}$ to $o_{7}$.

Fifth Scenario: Prediction of the CFAB based on the ITCF.

In this scenario, the CFAB is reflected by the following 8 feedbacks from the questionnaire:

1. "You intentionally avoid the purchase of disposable paper or plastic products for environmental reasons." (notation: $B_{1}$ )

2. "You intentionally avoid purchasing products with unnecessary packaging to preserve forests." (notation: $B_{2}$ )

3. "You intentionally purchase products manufactured or grown in an environmentally friendly manner to preserve to forests." (notation: $B_{3}$ )

4. "You buy eco-labelled products i.e., non-polluting products to save forests." (notation: $B_{4}$ )

5. "You practice foresting." (notation: $B_{5}$ )

6. "You have supported policy that encourages community foresting." (notation: $B_{6}$ )

7. "You talk to people in an effort to persuade that person to start foresting." (notation: $B_{7}$ )

8. "You set a positive environmental example (foresting) for your friends to follow." (notation: $B_{8}$ ) 
Each can take an integer value ranged from 1 to 7 .

As the information for each feedback needs to be preserved as well, take $\mathbf{B}=\left(B_{1} B_{2} B_{3} B_{4} B_{5} B_{6} B_{7} B_{8}\right)$, which represents all the feedbacks concerning CFAB.

Our aim in this scenario is thus to generate the best two stage ANN to predict B from $\mathbf{I}$ (see scenario 4), using our deep learning algorithm. There will be one extra input node that is always taken to be the constant 1 .

Hence, there will be altogether 8 input nodes, $x_{1}$ to $x_{8}$; and 8 output nodes, $y_{1}$ to $y_{8}$. Considering the caliber of our workstations, the number intermediate nodes are chosen to be the same as the number of output nodes, hence $o_{1}$ to $o_{8}$.

\section{Summary of Findings}

\subsection{Demographic Characteristics}

The data are collected from 420 poor families from rural areas in Malaysia. Among the respondents, the majority (239) were females (56.9\%). A total of 167 (31.8\%) respondents were between 41 to 50 years old, followed by $111(26.4 \%)$ who were 31 to 40 years old, 81 (19.3\%) who were 51 to 60 years old, $47(11.2 \%)$ who were between 20 to 30-year-old, and the remaining respondents were below 20 or over 60 years old. In terms of education, 251 respondents (59.8\%) accomplished secondary school, followed by $86(20.5 \%)$ who completed diploma level, 54 (12.9\%) completed primary school level, $23(5.5 \%)$ had an undergraduate degree, $2(0.5 \%)$ had a Master's degree, and 4 respondents $(1 \%)$ had never attended school. Among the sampled household heads, 349 respondents (majority) reported business as their main economic activity, while the remaining $71(16.9 \%)$ mentioned paid employment as their main economic activity. From the total of 420 respondents, 152 respondents (36.2\%) have two full-time sources of income, followed by 120 (28.6\%) with three sources of income, $62(14.8 \%)$ with four, $50(11.9 \%)$ with one, $27(6.4 \%)$ with five, $6(1.4 \%)$ with six, and only $3(0.7 \%)$ with seven sources of full-time income.

\subsection{Validity and Reliability}

Table 1 reveals the descriptive statistics of the studied variables. All variables contain Cronbach's alpha value more than 0.70 , which confirms that all items are reliable as shown in Table 1 (Hair et al., 2019). Moreover, the "composite reliability" values for all variables are more than 0.9 , which also indicates the reliability of the items used to measure the constructs (Hair et al., 2019). Furthermore, the Dillon-Goldstein rho values for all constructs are more than 0.9 , confirming the items' reliability.

Table 1. Reliability and validity.

\begin{tabular}{ccccccccc}
\hline Variables & No. Items & Mean & SD & CA & DG rho & CR & AVE & VIF \\
\hline PB & 6 & 4.226 & 0.572 & 0.893 & 0.907 & 0.918 & 0.651 & 1.144 \\
EL & 6 & 3.596 & 0.743 & 0.928 & 0.931 & 0.944 & 0.736 & 1.144 \\
NB & 6 & 3.374 & 0.743 & 0.930 & 0.935 & 0.945 & 0.739 & 1.676 \\
MO & 7 & 3.584 & 0.648 & 0.937 & 0.940 & 0.949 & 0.727 & 1.676 \\
PC & 6 & 3.780 & 0.674 & 0.901 & 0.920 & 0.924 & 0.670 & 1.000 \\
ATE & 6 & 3.427 & 0.668 & 0.938 & 0.939 & 0.951 & 0.763 & 1.348 \\
SUN & 5 & 3.350 & 0.667 & 0.892 & 0.900 & 0.920 & 0.698 & 1.512 \\
PBC & 7 & 3.346 & 0.668 & 0.924 & 0.924 & 0.939 & 0.688 & 1.683 \\
ITCF & 7 & 4.188 & 1.108 & 0.913 & 0.914 & 0.931 & 0.659 & 1.000 \\
CFAB & 8 & 4.403 & 0.560 & 0.965 & 0.967 & 0.970 & 0.802 & - \\
\hline
\end{tabular}

Note: PB: Perceived Benefits; EL: Eco-Literacy; NB: Normative Beliefs; MO: Motivation; PC: Perceived Control; ATE: Attitude towards Environment; SUN: Subjective Norms; PBC: Perceived Behavioral Control; ITCF: Intention towards Community Forestry; CFAB: Community Forestry Adoption Behaviour; SD: Standard Deviation; CA: Cronbach's Alpha; DG rho-Dillon-Goldstein's rho; CR—Composite Reliability; AVE-Average Variance Extracted; VIF-Variance Inflation Factors. 
The average variance extracted (AVE) values are found larger than recommended value of 0.50 , which confirms "convergent validity". Table 2 shows the confirmation of "discriminant validity" according to the Fornell-Larcker criterion as the AVE value for each construct is larger than the construct's highest squared correlation with other constructs. Using a value of 0.9 as the threshold for the heterotrait-monotrait ratio (HTMT), "discriminant validity is confirmed in the dataset.

Table 2. Discriminant validity.

\begin{tabular}{|c|c|c|c|c|c|c|c|c|c|c|}
\hline & PB & EL & NB & MO & PC & ATE & SUN & PBC & ITCF & CFAB \\
\hline \multicolumn{11}{|c|}{ Fornell-Larcker Criterion } \\
\hline $\mathrm{PB}$ & 0.807 & & & & & & & & & \\
\hline EL & 0.354 & 0.858 & & & & & & & & \\
\hline NB & 0.420 & 0.665 & 0.860 & & & & & & & \\
\hline $\mathrm{MO}$ & 0.221 & 0.505 & 0.635 & 0.852 & & & & & & \\
\hline PC & 0.379 & 0.508 & 0.601 & 0.528 & 0.819 & & & & & \\
\hline ATE & 0.381 & 0.426 & 0.450 & 0.433 & 0.514 & 0.874 & & & & \\
\hline SUN & 0.317 & 0.315 & 0.343 & 0.326 & 0.398 & 0.391 & 0.836 & & & \\
\hline PBC & 0.290 & 0.409 & 0.416 & 0.508 & 0.466 & 0.489 & 0.567 & 0.829 & & \\
\hline ITCF & 0.273 & 0.224 & 0.220 & 0.304 & 0.313 & 0.411 & 0.421 & 0.439 & 0.812 & \\
\hline CFAB & 0.217 & 0.264 & 0.223 & 0.283 & 0.296 & 0.442 & 0.344 & 0.402 & 0.604 & 0.895 \\
\hline \multicolumn{11}{|c|}{ Heterotrait-Monotrait Ratio (HTMT) } \\
\hline PB & - & & & & & & & & & \\
\hline EL & 0.389 & - & & & & & & & & \\
\hline NB & 0.456 & 0.722 & - & & & & & & & \\
\hline $\mathrm{MO}$ & 0.246 & 0.545 & 0.682 & - & & & & & & \\
\hline PC & 0.433 & 0.553 & 0.657 & 0.565 & - & & & & & \\
\hline ATE & 0.406 & 0.451 & 0.480 & 0.460 & 0.553 & - & & & & \\
\hline SUN & 0.353 & 0.339 & 0.367 & 0.349 & 0.446 & 0.426 & - & & & \\
\hline PBC & 0.324 & 0.440 & 0.449 & 0.545 & 0.498 & 0.524 & 0.618 & - & & \\
\hline ITCF & 0.295 & 0.243 & 0.243 & 0.332 & 0.350 & 0.444 & 0.464 & 0.479 & - & \\
\hline CFAB & 0.224 & 0.282 & 0.240 & 0.303 & 0.322 & 0.467 & 0.369 & 0.428 & 0.641 & - \\
\hline
\end{tabular}

Note: PB: Perceived Benefits; EL: Eco-Literacy; NB: Normative Beliefs; MO: Motivation; PC: Perceived Control; ATE: Attitude towards Environment; SUN: Subjective Norms; PBC: Perceived Behavioral Control; ITCF: Intention towards Community Forestry; CFAB: Community Forestry Adoption Behavior.

Table 3 illustrates that all the indicators' loadings are higher in value than the total cross-loadings, confirming sufficient discriminant validity. Finally, the variance inflation factor (VIF) values for all variables are less than 1.7 (see Table 1), showing the absence of any multicollinearity issue in the dataset [44].

Table 3. Loadings and cross-loading.

\begin{tabular}{ccccccccccc}
\hline & PB & EL & NB & MO & PC & ATE & SUN & PBC & ITCF & CFAB \\
\hline P1 & 0.812 & 0.267 & 0.362 & 0.178 & 0.313 & 0.395 & 0.201 & 0.213 & 0.263 & 0.227 \\
P2 & 0.826 & 0.276 & 0.362 & 0.164 & 0.319 & 0.311 & 0.255 & 0.205 & 0.211 & 0.177 \\
P3 & 0.819 & 0.314 & 0.320 & 0.145 & 0.307 & 0.298 & 0.263 & 0.181 & 0.205 & 0.167 \\
P4 & 0.839 & 0.286 & 0.297 & 0.139 & 0.274 & 0.267 & 0.289 & 0.217 & 0.188 & 0.155 \\
P5 & 0.817 & 0.297 & 0.342 & 0.212 & 0.294 & 0.299 & 0.320 & 0.307 & 0.253 & 0.167 \\
P6 & 0.721 & 0.285 & 0.343 & 0.244 & 0.329 & 0.232 & 0.223 & 0.307 & 0.179 & 0.133 \\
E1 & 0.284 & 0.827 & 0.562 & 0.404 & 0.439 & 0.358 & 0.303 & 0.342 & 0.190 & 0.220 \\
E2 & 0.343 & 0.853 & 0.568 & 0.427 & 0.454 & 0.414 & 0.307 & 0.383 & 0.212 & 0.226 \\
E3 & 0.327 & 0.881 & 0.544 & 0.419 & 0.424 & 0.382 & 0.277 & 0.352 & 0.213 & 0.265 \\
E4 & 0.323 & 0.870 & 0.584 & 0.440 & 0.427 & 0.335 & 0.229 & 0.327 & 0.164 & 0.233 \\
E5 & 0.277 & 0.860 & 0.573 & 0.429 & 0.426 & 0.361 & 0.229 & 0.349 & 0.187 & 0.222 \\
E6 & 0.261 & 0.855 & 0.596 & 0.484 & 0.445 & 0.330 & 0.270 & 0.346 & 0.177 & 0.185 \\
\hline
\end{tabular}


Table 3. Cont

\begin{tabular}{|c|c|c|c|c|c|c|c|c|c|c|}
\hline & PB & EL & NB & MO & PC & ATE & SUN & PBC & ITCF & CFAB \\
\hline N1 & 0.337 & 0.640 & 0.846 & 0.554 & 0.510 & 0.401 & 0.252 & 0.374 & 0.219 & 0.236 \\
\hline N2 & 0.321 & 0.612 & 0.839 & 0.533 & 0.485 & 0.362 & 0.241 & 0.363 & 0.195 & 0.171 \\
\hline N3 & 0.409 & 0.552 & 0.856 & 0.552 & 0.513 & 0.460 & 0.314 & 0.345 & 0.213 & 0.239 \\
\hline N4 & 0.404 & 0.537 & 0.852 & 0.500 & 0.483 & 0.392 & 0.315 & 0.286 & 0.169 & 0.171 \\
\hline N5 & 0.361 & 0.569 & 0.891 & 0.572 & 0.553 & 0.360 & 0.324 & 0.399 & 0.189 & 0.201 \\
\hline N6 & 0.323 & 0.548 & 0.874 & 0.568 & 0.554 & 0.346 & 0.304 & 0.386 & 0.160 & 0.137 \\
\hline M1 & 0.180 & 0.393 & 0.475 & 0.766 & 0.405 & 0.280 & 0.274 & 0.401 & 0.272 & 0.212 \\
\hline M2 & 0.203 & 0.445 & 0.515 & 0.785 & 0.434 & 0.295 & 0.247 & 0.401 & 0.238 & 0.223 \\
\hline M3 & 0.215 & 0.466 & 0.562 & 0.830 & 0.474 & 0.397 & 0.251 & 0.413 & 0.256 & 0.275 \\
\hline M4 & 0.158 & 0.431 & 0.553 & 0.895 & 0.445 & 0.399 & 0.297 & 0.482 & 0.270 & 0.285 \\
\hline M5 & 0.204 & 0.433 & 0.583 & 0.901 & 0.479 & 0.405 & 0.295 & 0.459 & 0.276 & 0.254 \\
\hline M6 & 0.188 & 0.408 & 0.544 & 0.894 & 0.461 & 0.385 & 0.307 & 0.439 & 0.256 & 0.211 \\
\hline M7 & 0.176 & 0.448 & 0.559 & 0.885 & 0.456 & 0.415 & 0.263 & 0.428 & 0.245 & 0.230 \\
\hline $\mathrm{R} 1$ & 0.355 & 0.329 & 0.420 & 0.268 & 0.669 & 0.317 & 0.308 & 0.227 & 0.226 & 0.185 \\
\hline $\mathrm{R} 2$ & 0.328 & 0.425 & 0.481 & 0.371 & 0.755 & 0.393 & 0.352 & 0.335 & 0.288 & 0.250 \\
\hline $\mathrm{R} 3$ & 0.312 & 0.409 & 0.507 & 0.480 & 0.850 & 0.446 & 0.323 & 0.383 & 0.260 & 0.247 \\
\hline $\mathrm{R} 4$ & 0.310 & 0.427 & 0.541 & 0.489 & 0.879 & 0.489 & 0.350 & 0.434 & 0.284 & 0.287 \\
\hline R5 & 0.296 & 0.462 & 0.516 & 0.463 & 0.888 & 0.452 & 0.332 & 0.438 & 0.250 & 0.244 \\
\hline R6 & 0.308 & 0.436 & 0.490 & 0.470 & 0.849 & 0.407 & 0.313 & 0.419 & 0.243 & 0.232 \\
\hline A1 & 0.265 & 0.403 & 0.385 & 0.413 & 0.444 & 0.839 & 0.304 & 0.412 & 0.374 & 0.410 \\
\hline A2 & 0.297 & 0.436 & 0.422 & 0.446 & 0.485 & 0.849 & 0.352 & 0.457 & 0.399 & 0.409 \\
\hline A3 & 0.326 & 0.316 & 0.371 & 0.376 & 0.396 & 0.863 & 0.351 & 0.420 & 0.365 & 0.400 \\
\hline $\mathrm{A} 4$ & 0.330 & 0.313 & 0.351 & 0.333 & 0.424 & 0.891 & 0.327 & 0.408 & 0.345 & 0.364 \\
\hline A5 & 0.397 & 0.380 & 0.414 & 0.333 & 0.470 & 0.901 & 0.352 & 0.415 & 0.323 & 0.370 \\
\hline A6 & 0.382 & 0.373 & 0.406 & 0.359 & 0.467 & 0.896 & 0.362 & 0.446 & 0.342 & 0.360 \\
\hline S1 & 0.188 & 0.174 & 0.217 & 0.214 & 0.285 & 0.275 & 0.794 & 0.409 & 0.334 & 0.247 \\
\hline $\mathrm{S} 2$ & 0.172 & 0.256 & 0.284 & 0.266 & 0.342 & 0.317 & 0.833 & 0.463 & 0.315 & 0.287 \\
\hline S3 & 0.327 & 0.226 & 0.230 & 0.170 & 0.278 & 0.352 & 0.801 & 0.377 & 0.396 & 0.340 \\
\hline $\mathrm{S} 4$ & 0.343 & 0.323 & 0.338 & 0.336 & 0.383 & 0.346 & 0.886 & 0.547 & 0.382 & 0.312 \\
\hline S5 & 0.273 & 0.316 & 0.345 & 0.352 & 0.364 & 0.340 & 0.861 & 0.552 & 0.334 & 0.254 \\
\hline Q1 & 0.234 & 0.263 & 0.287 & 0.357 & 0.361 & 0.384 & 0.523 & 0.752 & 0.402 & 0.369 \\
\hline Q2 & 0.255 & 0.334 & 0.348 & 0.390 & 0.378 & 0.408 & 0.557 & 0.780 & 0.390 & 0.394 \\
\hline Q3 & 0.177 & 0.322 & 0.308 & 0.436 & 0.379 & 0.371 & 0.431 & 0.825 & 0.338 & 0.338 \\
\hline Q4 & 0.240 & 0.386 & 0.365 & 0.440 & 0.399 & 0.432 & 0.432 & 0.849 & 0.329 & 0.294 \\
\hline Q5 & 0.290 & 0.362 & 0.403 & 0.470 & 0.428 & 0.429 & 0.441 & 0.854 & 0.375 & 0.313 \\
\hline Q6 & 0.243 & 0.358 & 0.348 & 0.434 & 0.383 & 0.415 & 0.448 & 0.880 & 0.357 & 0.323 \\
\hline Q7 & 0.235 & 0.345 & 0.348 & 0.414 & 0.372 & 0.392 & 0.449 & 0.858 & 0.347 & 0.297 \\
\hline $\mathrm{I} 1$ & 0.139 & 0.257 & 0.249 & 0.358 & 0.338 & 0.349 & 0.215 & 0.398 & 0.731 & 0.459 \\
\hline $\mathrm{I} 2$ & 0.128 & 0.226 & 0.235 & 0.342 & 0.316 & 0.347 & 0.256 & 0.419 & 0.755 & 0.467 \\
\hline I3 & 0.164 & 0.188 & 0.193 & 0.293 & 0.253 & 0.344 & 0.311 & 0.353 & 0.857 & 0.505 \\
\hline $\mathrm{I} 4$ & 0.232 & 0.143 & 0.163 & 0.216 & 0.254 & 0.304 & 0.382 & 0.338 & 0.865 & 0.487 \\
\hline I5 & 0.240 & 0.170 & 0.148 & 0.173 & 0.209 & 0.318 & 0.407 & 0.333 & 0.847 & 0.524 \\
\hline I6 & 0.326 & 0.162 & 0.148 & 0.194 & 0.231 & 0.357 & 0.406 & 0.328 & 0.822 & 0.505 \\
\hline I7 & 0.312 & 0.133 & 0.125 & 0.167 & 0.190 & 0.314 & 0.402 & 0.331 & 0.797 & 0.479 \\
\hline B1 & 0.123 & 0.315 & 0.261 & 0.323 & 0.356 & 0.425 & 0.255 & 0.386 & 0.476 & 0.847 \\
\hline B2 & 0.137 & 0.313 & 0.281 & 0.351 & 0.376 & 0.439 & 0.257 & 0.400 & 0.480 & 0.835 \\
\hline B3 & 0.126 & 0.269 & 0.232 & 0.302 & 0.320 & 0.438 & 0.299 & 0.389 & 0.519 & 0.902 \\
\hline B4 & 0.205 & 0.241 & 0.209 & 0.246 & 0.290 & 0.420 & 0.309 & 0.378 & 0.555 & 0.936 \\
\hline B5 & 0.210 & 0.205 & 0.149 & 0.230 & 0.243 & 0.361 & 0.326 & 0.350 & 0.565 & 0.926 \\
\hline B6 & 0.245 & 0.188 & 0.172 & 0.203 & 0.221 & 0.383 & 0.333 & 0.315 & 0.579 & 0.919 \\
\hline B7 & 0.242 & 0.175 & 0.152 & 0.182 & 0.170 & 0.348 & 0.338 & 0.336 & 0.564 & 0.891 \\
\hline B8 & 0.242 & 0.213 & 0.170 & 0.223 & 0.182 & 0.369 & 0.335 & 0.345 & 0.571 & 0.902 \\
\hline
\end{tabular}

Note: PB: Perceived Benefits; EL: Eco-Literacy; NB: Normative Beliefs; MO: Motivation; PC: Perceived Control; ATE: Attitude towards Environment; SUN: Subjective Norms; PBC: Perceived Behavioral Control; ITCF: Intention towards Community Forestry; CFAB: Community Forestry Adoption Behaviour. The Italic values in the matrix above are the item loadings and others are cross-loadings. 


\subsection{Path Analysis}

The results of path analysis revealed the coefficient value for PB on the ATE, which was 0.263 with a $p$-value of 0.000 . It can be said that the head of low-income household's level of perceived benefit in Malaysia has influence on their attitude towards the environment. The result also indicates that EL affects the ATE among the underprivileged households in Malaysia with a Beta coefficient of 0.333 and $p$-value of 0.000 . The head of poor household's level of EL has a significant positive effect on their attitude towards the environment. The results indicate that EL has a relatively higher effect on the attitude towards the environment compared to perceived benefit. Moreover, the $f^{2}$ value of 0.080 shows a small effect of perceived benefit on the ATE among the underprivileged households in Malaysia. The $f^{2}$ value of 0.128 indicates a small to medium effect of EL on the ATE among the underprivileged households in coastal Malaysia, which is also comparatively greater than PB. The $r^{2}$ value, representing the degree of explained variance, is 0.242 , which means that $24.2 \%$ of the variation in the respondents' ATE can be explained by their level of PB and EL. Finally, the $Q^{2}$ value of 0.175 indicates that the respondents' level of PB and EL have medium predictive relevance for the respondents' attitude towards the environment.

The coefficient value for NB on SUN is 0.228 with a $p$-value of 0.000 . The findings indicate that underprivileged households' level of NB have a significant positive effect on their SUN. The $f^{2}$ value of 0.036 indicates small effects of NB on SUN among the underprivileged households in Malaysia, which is also comparatively greater than MO. For MO, the coefficient value on SUN among the poor households in Malaysia is 0.181 with a p-value of 0.001 . It can be said that underprivileged households' level of MO to comply has a significant positive effect on their SUN. The $f^{2}$ value of 0.023 indicates small effects of MO on SUN among the underprivileged households in Malaysia. The results indicate that NB has a relatively higher effect on SUN compared to MO. Moreover, the $r^{2}$ value of 0.137 indicates that $13.7 \%$ of the variation in the respondents' SUN can be explained by their level of NB and MO. Finally, the $Q^{2}$ value of 0.086 indicates that the respondents' level of NB and MO have small to medium predictive relevance for the respondents' SUN.

The coefficient value for PC on PBC among the underprivileged households in Malaysia is 0.466 with a $p$-value of 0.000 . The findings indicate that the underprivileged households' level of PC has a significant positive effect on their PBC. Moreover, the $f^{2}$ value of 0.278 indicates moderate to strong effect of PC on PBC among the underprivileged households in Malaysia. The $r^{2}$ value of 0.217 indicates that $21.7 \%$ proportion of the variation in the respondents' $\mathrm{PBC}$ can be explained by their PC. Finally, the $Q^{2}$ value of 0.141 indicates that the respondents' $P C$ has small to medium predictive relevance for the respondents' $\mathrm{PBC}$.

The path coefficients, in Table 4, show that the value for ATE on ITCF among the underprivileged households is 0.225 with a $p$-value of 0.000 . The findings indicate that the underprivileged households' attitude towards the environment has a significant positive effect on their ITCF. Likewise, the $f^{2}$ value of 0.052 is relatively higher than SUN and PBC, indicating a small effect of ATE on the ITCF among the underprivileged households in Malaysia.

The coefficient value for SUN on the ITCF is 0.217 with a $p$-value of 0.000 . The findings indicate that SUN have a significant positive effect on the ITCF across the sample. Moreover, the $f^{2}$ value of 0.043 is higher than PBC, indicating a small effect of SUN on the ITCF among the respondents.

The values for PBC on ITCF are 0.206 with a $p$-value of 0.000 . The findings indicate that underprivileged households' level of PBC has a significant positive effect on their ITCF. Furthermore, the $f^{2}$ value of 0.035 indicates a small effect of SUN on the ITCF across the sample of the study.

The results indicate that the attitude towards the environment has a relatively higher effect on the ITCF compared to SUN and PBC. The $r^{2}$ value of 0.274 indicates that $27.4 \%$ of the variation in the respondents' ITCF can be explained by their level of ATE, SUN, and PBC. Lastly, the $Q^{2}$ value of 0.166 shows that the respondents' level of ATE, SUN, and PBC have medium predictive relevance on their ITCF. 
Table 4. Path coefficients.

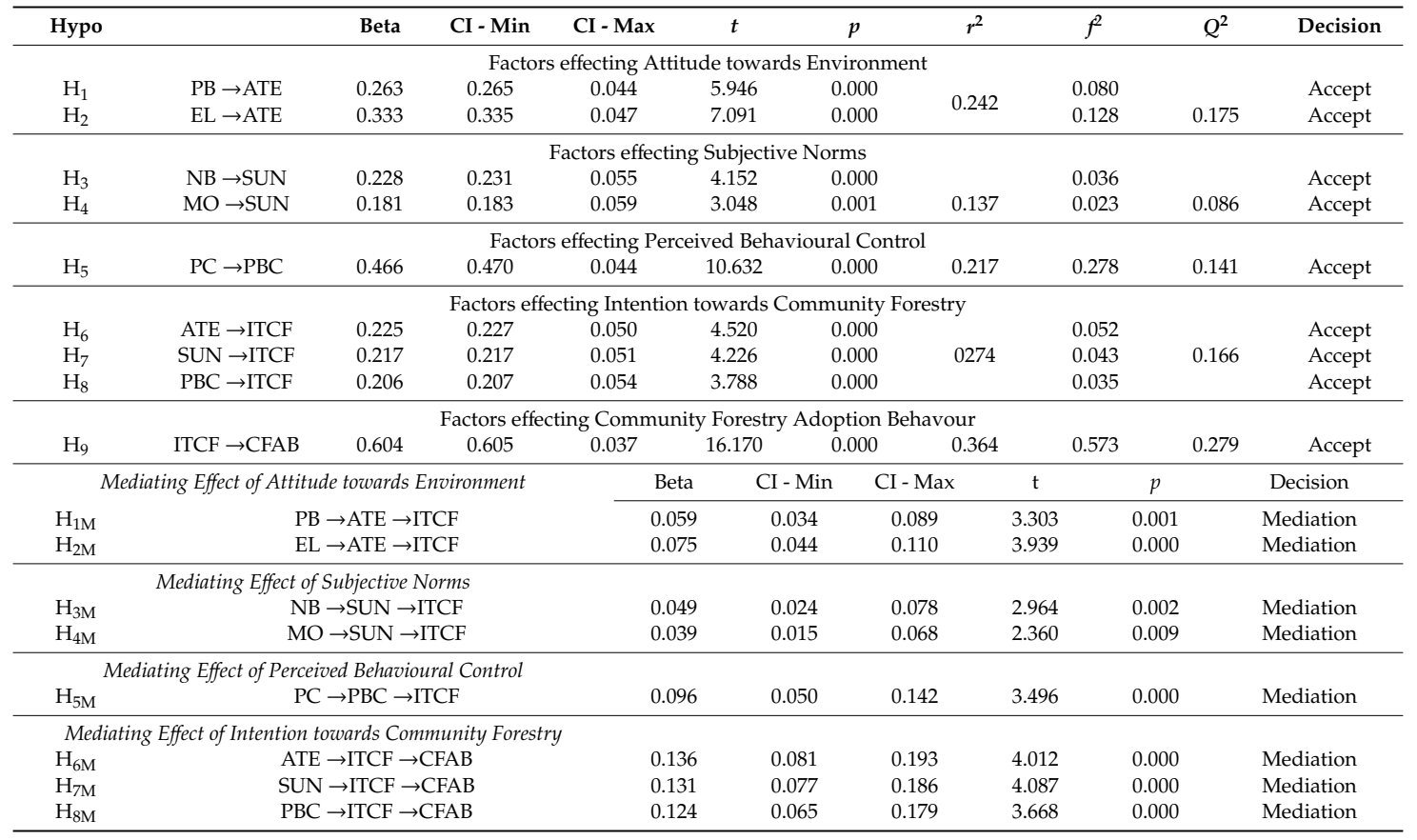

Note: PB: Perceived Benefits; EL: Eco-Literacy; NB: Normative Beliefs; MO: Motivation; PC: Perceived Control; ATE: Attitude towards Environment; SUN: Subjective Norms; PBC: Perceived Behavioral Control; ITCF: Intention towards Community Forestry; CFAB: Community Forestry Adoption Behavior. Source: Author's data analysis.

Finally, the coefficient value for ITCF on CFAB is 0.604 with a $p$-value of 0.000 . The findings indicate that the underprivileged households' ITCF has a significant positive effect on the CFAB. Furthermore, the $f^{2}$ value of 0.573 shows a large effect of the ITCF on CFAB among the respondents. The $r^{2}$ value of 0.364 indicates that a significant proportion (36.4\%) of the variation in the respondents' CFAB can be explained by their level of ITCF. Lastly, the $Q^{2}$ value of 0.229 shows that the respondents' level of ITCF has medium predictive relevance for the CFAB.

\subsection{Mediating Effects}

Findings reveal that PB have a significant positive indirect effect on the ITCF ( $p$-values $>0.05$ ) among the respondents (see Table 4). This result confirms that the ATE can mediate the link between PB and ITCF. EL has a significant positive indirect effect on the ITCF across the sample of the study, confirming that the ATE mediates the association between EL and ITCF. For the mediating effect of SUN, the findings reveal that NB has a significant indirect effect on the ITCF among the underprivileged households in Malaysia. This result confirms that SUN mediate the effect of NB on the ITCF. Moreover, there is a significant positive indirect effect of $\mathrm{MO}$ on the ITCF, confirming the mediating effect of SUN on the association between $\mathrm{MO}$ and ITCF.

The findings for PC reveal a significant positive indirect effect on the ITCF. This result confirms that PBC mediates the relationship between PC and ITCF. The findings further reveal that the ATE has a significant positive indirect effect ( $p$-values $>0.05$ ) on $C F A B$ among the underprivileged households in Malaysia. This result confirms that the ITCF mediates the relationship between the ATE and CFAB. SUN have a significant positive indirect effect on the forestry adoption behavior of the community, confirming that the ITCF mediates the relationship between SUN and CFAB. Lastly, the findings for $\mathrm{PBC}$ reveal a significant positive indirect effect on $\mathrm{CFAB}$ among the respondents. This result confirms that the ITCF mediates the link between PBC and CFAB. 


\subsection{Importance-Performance Matrix Analysis (IPMA)}

Table 5 shows the total effect values and performance values. It reveals that the ATE, followed by SUN, PBC, PC, PB, EL, NB, and MO, are the most important factors influencing the ITCF. Furthermore, the ITCF, followed by the ATE, SUN, PBC, PC, PB, EL, NB, and MO are the most important factors for the CFAB.

Table 5. Performance and total effects.

\begin{tabular}{ccccc}
\hline Target Construct & \multicolumn{2}{c}{ ITCF } & \multicolumn{2}{c}{ CFAB } \\
\hline Variables & Total Effect & Performance & Total Effect & Performance \\
\hline PB & 0.070 & 74.574 & 0.070 & 74.574 \\
EL & 0.068 & 62.796 & 0.068 & 62.796 \\
NB & 0.046 & 66.655 & 0.046 & 66.655 \\
MO & 0.035 & 49.815 & 0.035 & 49.815 \\
PC & 0.097 & 64.112 & 0.097 & 64.112 \\
ATE & 0.224 & 59.135 & 0.224 & 59.135 \\
SUN & 0.217 & 60.665 & 0.217 & 60.665 \\
PBC & 0.208 & 58.774 & 0.208 & 58.774 \\
ITCF & - & - & 1.000 & 55.991
\end{tabular}

Note: PB: Perceived Benefits; EL: Eco-Literacy; NB: Normative Beliefs; MO: Motivation; PC: Perceived Control; ATE: Attitude towards Environment; SUN: Subjective Norms; PBC: Perceived Behavioral Control; ITCF: Intention towards Community Forestry; CFAB: Community Forestry Adoption Behavior.

\section{Analysis from the ANN}

The first scenario focused on the prediction of the ATE based on PB and EL. The values of all the synaptic weights in the ANN for the first scenario, obtained through the deep learning algorithm, as well as all the feedbacks, are presented in Table 6 . The synaptic weight connecting the $a$-th input node and the $b$-th intermediate node is denoted as $w_{a, b}$, whereas the synaptic weight connecting the $b$-th intermediate node and the $c$-th output node is denoted as $v_{b, c}$. Moreover, the feedback corresponds each of the $a$-th input node and each of the $c$-th output node are also given on the top row of the Table 6 . As noted in Table 6, $P_{1}$ to $P_{6}$ are all the feedbacks that reflect $\mathrm{PB}, E_{1}$ to $E_{6}$ are all the feedbacks that reflect EL, and $A_{1}$ to $A_{6}$ are all the feedbacks that reflect ATE, as mentioned in the previous passages of this article.

The RMSE value of 0.746 for the first scenario (as presented in Table 6) show the high predictive accuracy of the model. Associated sensitivity analysis helps to evaluate the contribution of each exogenous construct on the formulation of the ATE for the first scenario. Normalized importance percentage based on the fraction of relative importance for each construct depicted in Table 6. The total contribution of the input neuron on the endogenous construct (i.e., ATE) the most contributing construct is PB, followed by EL.

The second scenario focused on the prediction of the SUN based on NB and MO. The values of all the synaptic weights in the ANN for the second scenario, obtained through the deep learning algorithm presented in Table 7. Likewise, the synaptic weight connecting the $a$-th input node and the $b$-th intermediate node is denoted as $w_{a, b}$, whereas the synaptic weight connecting the $b$-th intermediate node and the $c$-th output node is denoted as $v_{b, c}$. Moreover, the feedback corresponds each of the $a$-th input node and each of the $c$-th output node are also given on the top row of the Table 7 . It is worth noting that $N_{1}$ to $N_{6}$ are all the feedbacks that reflect NB, $M_{1}$ to $M_{7}$ are all the feedbacks that reflect $\mathrm{MO}$, and $S_{1}$ to $S_{5}$ are all the feedbacks that reflect $S U N$, as mentioned in the previous passages of this article. 
Table 6. Results for the first scenario.

\begin{tabular}{|c|c|c|c|c|c|c|c|c|c|c|c|c|c|}
\hline Feedback & $P_{1}$ & $P_{2}$ & $P_{3}$ & $P_{4}$ & $P_{5}$ & $P_{6}$ & $E_{1}$ & $E_{2}$ & $E_{3}$ & $E_{4}$ & $E_{5}$ & $E_{6}$ & 1 \\
\hline $\begin{array}{c}w_{a, b} \\
a \\
b\end{array}$ & 1 & 2 & 3 & 4 & 5 & 6 & 7 & 8 & 9 & 10 & 11 & 12 & 13 \\
\hline $\begin{array}{l}1 \\
2 \\
3 \\
4 \\
5 \\
6\end{array}$ & $\begin{array}{l}0.090 \\
0.126 \\
0.109 \\
0.162 \\
0.127 \\
0.142\end{array}$ & $\begin{array}{l}0.069 \\
0.013 \\
0.123 \\
0.045 \\
0.112 \\
0.052\end{array}$ & $\begin{array}{l}0.080 \\
0.055 \\
0.050 \\
0.089 \\
0.063 \\
0.071\end{array}$ & $\begin{array}{c}0.050 \\
0.004 \\
0.003 \\
-0.043 \\
-0.023 \\
-0.008\end{array}$ & $\begin{array}{l}0.080 \\
0.125 \\
0.138 \\
0.154 \\
0.144 \\
0.177\end{array}$ & $\begin{array}{l}0.085 \\
0.065 \\
0.054 \\
0.100 \\
0.100 \\
0.081\end{array}$ & $\begin{array}{l}0.068 \\
0.003 \\
0.069 \\
0.008 \\
0.008 \\
0.055\end{array}$ & $\begin{array}{l}0.086 \\
0.148 \\
0.100 \\
0.158 \\
0.154 \\
0.101\end{array}$ & $\begin{array}{l}0.100 \\
0.126 \\
0.096 \\
0.127 \\
0.090 \\
0.098\end{array}$ & $\begin{array}{c}0.056 \\
0.044 \\
0.006 \\
-0.010 \\
0.020 \\
-0.042\end{array}$ & $\begin{array}{l}0.075 \\
0.127 \\
0.167 \\
0.152 \\
0.132 \\
0.178\end{array}$ & $\begin{array}{l}0.077 \\
0.010 \\
0.015 \\
0.012 \\
0.012 \\
0.026\end{array}$ & $\begin{array}{l}0.077 \\
0.092 \\
0.077 \\
0.062 \\
0.100 \\
0.085\end{array}$ \\
\hline $\begin{array}{c}\text { Feedback } \\
v_{b, c} \\
c \\
b\end{array}$ & $\begin{array}{c}A_{1} \\
1\end{array}$ & $\begin{array}{c}A_{2} \\
2\end{array}$ & $\begin{array}{c}A_{3} \\
3\end{array}$ & $\begin{array}{c}A_{4} \\
4\end{array}$ & $\begin{array}{c}A_{5} \\
5\end{array}$ & $\begin{array}{c}A_{6} \\
6\end{array}$ & & & & & & & \\
\hline $\begin{array}{l}1 \\
2 \\
3 \\
4 \\
5 \\
6\end{array}$ & $\begin{array}{c}0.988 \\
0.005 \\
-0.101 \\
0.126 \\
-0.004 \\
-0.014\end{array}$ & $\begin{array}{c}-0.154 \\
0.906 \\
0.249 \\
0.324 \\
-0.276 \\
-0.031\end{array}$ & $\begin{array}{c}-0.063 \\
0.019 \\
0.911 \\
0.041 \\
0.101 \\
-0.010\end{array}$ & $\begin{array}{c}-0.021 \\
-0.065 \\
-0.052 \\
0.836 \\
0.517 \\
-0.225\end{array}$ & $\begin{array}{c}0.023 \\
-0.058 \\
-0.091 \\
-0.172 \\
1.498 \\
-0.210\end{array}$ & $\begin{array}{c}0.074 \\
-0.085 \\
0.044 \\
-0.168 \\
0.175 \\
0.959\end{array}$ & & & & & & & \\
\hline \multicolumn{14}{|c|}{$\begin{array}{l}\text { Sample Size, } n=420 \\
\text { SSE }=1401 \\
\text { RMSE }=0.746 \\
\text { age Synaptic Weight }=0.105\end{array}$} \\
\hline \multicolumn{14}{|c|}{$\begin{array}{l}\text { Relative Sensitivity of the Two Factors } \\
\text { EL }\end{array}$} \\
\hline 1.000 & 0.966 & & & & & & & & & & & & \\
\hline
\end{tabular}

Table 7. Second scenario.

\begin{tabular}{|c|c|c|c|c|c|c|c|c|c|c|c|c|c|c|}
\hline Feedback & $N_{1}$ & $\mathrm{~N}_{2}$ & $N_{3}$ & $N_{4}$ & $N_{5}$ & $N_{6}$ & $M_{1}$ & $M_{2}$ & $M_{3}$ & $M_{4}$ & $M_{5}$ & $M_{6}$ & $M_{7}$ & 1 \\
\hline $\begin{array}{c}w_{a, b} \\
a \\
b\end{array}$ & 1 & 2 & 3 & 4 & 5 & 6 & 7 & 8 & 9 & 10 & 11 & 12 & 13 & 14 \\
\hline $\begin{array}{l}1 \\
2 \\
3 \\
4 \\
5\end{array}$ & $\begin{array}{c}0.021 \\
-0.039 \\
0.092 \\
0.089 \\
0.113\end{array}$ & $\begin{array}{l}0.040 \\
0.075 \\
0.047 \\
0.033 \\
0.030\end{array}$ & $\begin{array}{l}0.000 \\
0.104 \\
0.098 \\
0.107 \\
0.040\end{array}$ & $\begin{array}{l}0.197 \\
0.146 \\
0.080 \\
0.064 \\
0.160\end{array}$ & $\begin{array}{c}0.038 \\
-0.002 \\
0.064 \\
0.058 \\
0.036\end{array}$ & $\begin{array}{l}0.084 \\
0.116 \\
0.082 \\
0.085 \\
0.057\end{array}$ & $\begin{array}{l}0.200 \\
0.150 \\
0.093 \\
0.087 \\
0.114\end{array}$ & $\begin{array}{l}0.008 \\
0.023 \\
0.057 \\
0.050 \\
0.081\end{array}$ & $\begin{array}{l}0.105 \\
0.070 \\
0.079 \\
0.057 \\
0.004\end{array}$ & $\begin{array}{l}0.035 \\
0.104 \\
0.057 \\
0.113 \\
0.183\end{array}$ & $\begin{array}{c}-0.081 \\
-0.077 \\
0.032 \\
0.072 \\
-0.037\end{array}$ & $\begin{array}{l}0.305 \\
0.200 \\
0.168 \\
0.057 \\
0.161\end{array}$ & $\begin{array}{c}-0.086 \\
0.008 \\
0.000 \\
0.057 \\
0.001\end{array}$ & $\begin{array}{l}0.100 \\
0.100 \\
0.086 \\
0.071 \\
0.114\end{array}$ \\
\hline $\begin{array}{l}\text { Feedback } \\
v_{b, c} \\
c \\
b\end{array}$ & $\begin{array}{c}S_{1} \\
1\end{array}$ & $\begin{array}{c}S_{2} \\
2\end{array}$ & $\begin{array}{c}S_{3} \\
3\end{array}$ & $\begin{array}{c}S_{4} \\
4\end{array}$ & $\begin{array}{c}S_{5} \\
5\end{array}$ & & & & & & & & & \\
\hline $\begin{array}{l}1 \\
2 \\
3 \\
4 \\
5\end{array}$ & $\begin{array}{c}0.889 \\
0.224 \\
0.139 \\
-0.312 \\
0.070\end{array}$ & $\begin{array}{c}0.104 \\
0.956 \\
0.060 \\
-0.183 \\
0.063\end{array}$ & $\begin{array}{c}-0.183 \\
0.221 \\
0.988 \\
-0.110 \\
0.084\end{array}$ & $\begin{array}{c}0.021 \\
-0.019 \\
0.034 \\
0.973 \\
-0.009\end{array}$ & $\begin{array}{c}-0.111 \\
0.153 \\
-0.224 \\
0.174 \\
1.010\end{array}$ & & & & & & & & & \\
\hline \multicolumn{15}{|c|}{$\begin{array}{c}\text { Sample Size, } n=420 \\
\text { SSE }=1519 \\
\text { RMSE }=0.850 \\
\text { Average Synaptic Weight }=0.106\end{array}$} \\
\hline \multicolumn{15}{|c|}{$\begin{array}{cc} & \text { Relative Sensitivity of the Two Factors } \\
\text { NB } & \text { MO } \\
\end{array}$} \\
\hline 0.533 & 1.000 & & & & & & & & & & & & & \\
\hline
\end{tabular}

The RMSE value of 0.850 for the second scenario (as presented in Table 7) shows the high predictive accuracy of the model. Associated sensitivity analysis helps to evaluate the contribution of each exogenous construct on the formulation of the SUN for the second scenario. Normalized importance percentage based on the fraction of relative importance for each construct depicted in Table 6 . The total contribution of the input neuron on the endogenous construct (i.e., SUN), the most contributing construct, is $\mathrm{MO}$, followed by NB.

The third scenario focused on the prediction of the perceived behavioral control (PBC) based on PC. The values of all the synaptic weights in the ANN for the third scenario, obtained through the deep learning algorithm, are presented in Table 8. Likewise, the synaptic weight connecting the $a$-th input 
node and the $b$-th intermediate node is denoted as $w_{a, b}$, whereas the synaptic weight connecting the $b$-th intermediate node and the $c$-th output node is denoted as $v_{b, c}$. Moreover, the feedback corresponds each of the $a$-th input node and each of the $c$-th output node are also given on the top row of the Table 8. It is worth noting that $R_{1}$ to $R_{6}$ are all the feedbacks that reflect PC, whereas $Q_{1}$ to $Q_{7}$ are all the feedbacks that reflect PBC, as mentioned in the previous passages of this article. The RMSE value of 0.794 for the third scenario (as presented in Table 8) shows the high predictive accuracy of the model.

Table 8. Results for the third scenario.

\begin{tabular}{|c|c|c|c|c|c|c|c|}
\hline Feedback & $R_{1}$ & $R_{2}$ & $R_{3}$ & $R_{4}$ & $R_{5}$ & $R_{6}$ & 1 \\
\hline $\begin{array}{c}w_{a, b} \\
a \\
b\end{array}$ & 1 & 2 & 3 & 4 & 5 & 6 & 7 \\
\hline 1 & 0.200 & 0.100 & 0.114 & 0.171 & 0.129 & 0.143 & 0.200 \\
\hline 2 & 0.214 & 0.071 & 0.100 & 0.186 & 0.179 & 0.107 & 0.200 \\
\hline 3 & 0.114 & 0.057 & 0.129 & 0.171 & 0.171 & 0.186 & 0.171 \\
\hline 4 & 0.114 & 0.143 & 0.100 & 0.186 & 0.129 & 0.171 & 0.229 \\
\hline 5 & 0.200 & 0.143 & 0.043 & 0.200 & 0.157 & 0.129 & 0.129 \\
\hline 6 & 0.100 & 0.143 & 0.114 & 0.243 & 0.129 & 0.118 & 0.236 \\
\hline 7 & 0.125 & 0.161 & 0.129 & 0.157 & 0.200 & 0.086 & 0.171 \\
\hline $\begin{array}{c}\text { Feedback } \\
v_{b, c}\end{array}$ & $Q_{1}$ & $Q_{2}$ & $Q_{3}$ & $Q_{4}$ & $Q_{5}$ & $Q_{6}$ & $Q_{7}$ \\
\hline $\begin{array}{l}c, c \\
c \\
b\end{array}$ & 1 & 2 & 3 & 4 & 5 & 6 & 7 \\
\hline 1 & 0.645 & -0.263 & -1.118 & -0.965 & -0.843 & 0.190 & -0.438 \\
\hline 2 & 0.305 & 1.915 & 1.468 & 2.115 & 0.900 & 0.890 & 0.623 \\
\hline 3 & -0.185 & -0.845 & 0.910 & -1.070 & -0.460 & -0.555 & -0.835 \\
\hline 4 & 0.485 & 1.585 & 0.435 & 3.695 & 1.023 & 2.005 & 1.425 \\
\hline 5 & -0.350 & -1.085 & -0.910 & -2.620 & 0.575 & -2.155 & -0.800 \\
\hline 6 & 0.570 & 0.710 & 0.325 & 0.505 & 0.510 & 1.803 & 0.565 \\
\hline 7 & -0.470 & -1.040 & -0.110 & -0.670 & -0.715 & -1.178 & 0.450 \\
\hline \multicolumn{8}{|c|}{$\begin{array}{l}\text { Sample Size, } n=420 \\
\quad \text { SSE }=1855 \\
\text { RMSE }=0.794 \\
\text { age Synaptic Weight }=0.145\end{array}$} \\
\hline
\end{tabular}

The fourth scenario focused on the prediction of the ITCF based on ATE, SUN and PBC. Table 9 gives the values of all the synaptic weights in the ANN for the fourth scenario, obtained through the deep learning algorithm. Likewise, the synaptic weight connecting the $a$-th input node and the $b$-th intermediate node is denoted as $w_{a, b}$, whereas the synaptic weight connecting the $b$-th intermediate node and the $c$-th output node is denoted as $v_{b, c}$. Moreover, the feedback corresponds each of the $a$-th input node and each of the $c$-th output nodes are also given on the top row of the Table 9. It is worth noting that $A_{1}$ to $A_{6}$ are all the feedbacks that reflect ATE, $S_{1}$ to $S_{5}$ are all the feedbacks that reflect SUN, $Q_{1}$ to $Q_{7}$ are all the feedbacks that reflect PBC, and $I_{1}$ to $I_{7}$ are all the feedbacks that reflect ITCF, as mentioned in the previous passages of this article.

The RMSE value of 0.781 for the fourth scenario (as presented in Table 9) shows the high predictive accuracy of the model. Associated sensitivity analysis helps to evaluate the contribution of each exogenous construct on the formulation of the ITCF for the fourth scenario. Normalized importance percentage based on the fraction of relative importance for each construct is depicted in Table 9. The total contribution of the input neuron on the endogenous construct (i.e., ITCF) the most contributing construct, is ATE, followed by SUN and PBC. 
Table 9. Results for the fourth scenario.

\begin{tabular}{|c|c|c|c|c|c|c|c|c|c|c|}
\hline Feedback & $A_{1}$ & $A_{2}$ & $A_{3}$ & $A_{4}$ & $A_{5}$ & $A_{6}$ & $S_{1}$ & $S_{2}$ & $S_{3}$ & $S_{4}$ \\
\hline $\begin{array}{c}w_{a, b} \\
a \\
b\end{array}$ & 1 & 2 & 3 & 4 & 5 & 6 & 7 & 8 & 9 & 10 \\
\hline 1 & 0.042 & 0.032 & 0.005 & 0.074 & -0.008 & 0.071 & 0.074 & 0.037 & 0.053 & 0.084 \\
\hline 2 & 0.032 & 0.037 & 0.013 & 0.013 & 0.047 & 0.063 & 0.074 & 0.042 & 0.021 & 0.079 \\
\hline 3 & 0.026 & 0.053 & 0.068 & 0.076 & 0.012 & 0.064 & 0.032 & 0.068 & 0.063 & 0.074 \\
\hline 4 & 0.053 & 0.058 & 0.058 & 0.032 & 0.079 & 0.016 & 0.095 & 0.016 & 0.058 & 0.116 \\
\hline 5 & -0.005 & 0.116 & 0.047 & 0.097 & 0.041 & 0.010 & 0.084 & 0.026 & 0.053 & 0.084 \\
\hline 6 & 0.095 & 0.041 & 0.101 & 0.144 & 0.066 & -0.086 & 0.084 & -0.007 & 0.161 & 0.105 \\
\hline 7 & 0.004 & 0.128 & 0.138 & 0.093 & -0.012 & 0.007 & 0.098 & 0.020 & 0.123 & 0.052 \\
\hline $\begin{array}{c}\text { Feedback } \\
w_{a, b}\end{array}$ & $S_{5}$ & $Q_{1}$ & $Q_{2}$ & $Q_{3}$ & $Q_{4}$ & $Q_{5}$ & $Q_{6}$ & $Q_{7}$ & 1 & \\
\hline $\begin{array}{l}a \\
b\end{array}$ & 11 & 12 & 13 & 14 & 15 & 16 & 17 & 18 & 19 & \\
\hline 1 & 0.005 & 0.089 & 0.011 & 0.084 & 0.016 & 0.061 & 0.095 & 0.024 & 0.042 & \\
\hline 2 & 0.021 & 0.053 & 0.053 & 0.092 & 0.039 & 0.060 & 0.046 & 0.053 & 0.053 & \\
\hline 3 & 0.026 & 0.111 & 0.000 & 0.058 & 0.041 & 0.062 & 0.039 & 0.058 & 0.053 & \\
\hline 4 & -0.021 & 0.100 & 0.011 & 0.064 & 0.041 & 0.084 & -0.021 & 0.095 & 0.074 & \\
\hline 5 & 0.021 & 0.074 & 0.039 & 0.050 & 0.047 & 0.024 & 0.063 & 0.071 & 0.058 & \\
\hline 6 & -0.066 & 0.084 & 0.011 & 0.032 & 0.016 & 0.118 & 0.000 & 0.095 & 0.058 & \\
\hline 7 & 0.020 & 0.105 & 0.024 & 0.061 & -0.007 & 0.071 & -0.014 & 0.089 & 0.089 & \\
\hline Feedback & $I_{1}$ & $I_{2}$ & $I_{3}$ & $I_{4}$ & $I_{5}$ & $I_{6}$ & $I_{7}$ & & & \\
\hline $\begin{array}{c}v_{b, c} \\
c \\
b\end{array}$ & 1 & 2 & 3 & 4 & 5 & 6 & 7 & & & \\
\hline 1 & 0.979 & -0.103 & 0.047 & 0.236 & 0.106 & 0.242 & 0.489 & & & \\
\hline 2 & 0.026 & 1.103 & -0.016 & -0.191 & -0.103 & -0.171 & -0.408 & & & \\
\hline 3 & 0.053 & -0.038 & 0.850 & -0.521 & -0.058 & -0.304 & 0.224 & & & \\
\hline 4 & 0.049 & 0.001 & 0.103 & 1.488 & 0.063 & 0.271 & 0.084 & & & \\
\hline 5 & -0.111 & 0.036 & -0.014 & -0.078 & 1.010 & -0.086 & -0.371 & & & \\
\hline 6 & -0.048 & -0.018 & 0.019 & -0.026 & -0.015 & 1.010 & 0.246 & & & \\
\hline 7 & 0.053 & 0.018 & 0.012 & 0.091 & 0.028 & 0.078 & 0.775 & & & \\
\hline \multicolumn{11}{|c|}{$\begin{array}{c}\text { Sample Size, } n=420 \\
\text { SSE }=1792 \\
\text { RMSE }=0.781 \\
\text { erage Synaptic Weight }=0.077\end{array}$} \\
\hline \multicolumn{11}{|c|}{ Relative Sensitivity of the Three Factors } \\
\hline $\begin{array}{l}\text { ATE } \\
1.000\end{array}$ & $\begin{array}{l}\text { SUN } \\
0.923\end{array}$ & $\begin{array}{l}\text { PBC } \\
0.901\end{array}$ & & & & & & & & \\
\hline
\end{tabular}

The fifth scenario focused on the prediction of the CFAB based on the intention towards ITCF. The values of all the synaptic weights in the ANN for the fifth scenario, obtained through the deep learning algorithm, is presented in Table 10. Likewise, the synaptic weight connecting the $a$-th input node and the $b$-th intermediate node is denoted as $w_{a, b}$, whereas the synaptic weight connecting the $b$-th intermediate node and the $c$-th output node is denoted as $v_{b, c}$. Moreover, the feedback corresponds each of the $a$-th input node and each of the $c$-th output node are also given on the top row of the Table 10. As noted in Table $10, I_{1}$ to $I_{7}$ are all the feedbacks that reflect ITCF, and $B_{1}$ to $B_{8}$ are all the feedbacks that reflect CFAB, as mentioned in the previous passages of this article. The RMSE value of 1.043 for the fifth scenario (as presented in Table 10) shows the high predictive accuracy of the model. 
Table 10. Fifth scenario.

\begin{tabular}{|c|c|c|c|c|c|c|c|c|}
\hline Feedback & $I_{1}$ & $I_{2}$ & $I_{3}$ & $I_{4}$ & $I_{5}$ & $I_{6}$ & $I_{7}$ & 1 \\
\hline $\begin{array}{c}w_{a, b} \\
a \\
b\end{array}$ & 1 & 2 & 3 & 4 & 5 & 6 & 7 & 8 \\
\hline 1 & 0.197 & 0.119 & 0.152 & 0.133 & 0.113 & 0.263 & 0.050 & 0.150 \\
\hline 2 & 0.250 & 0.169 & 0.231 & 0.113 & 0.113 & 0.113 & 0.100 & 0.138 \\
\hline 3 & 0.213 & 0.138 & 0.175 & 0.150 & 0.213 & 0.163 & 0.100 & 0.125 \\
\hline 4 & 0.184 & 0.166 & 0.197 & 0.153 & 0.188 & 0.127 & 0.148 & 0.188 \\
\hline 5 & 0.163 & 0.209 & 0.153 & 0.113 & 0.238 & 0.173 & 0.164 & 0.113 \\
\hline 6 & 0.111 & 0.177 & 0.150 & 0.250 & 0.150 & 0.200 & 0.188 & 0.163 \\
\hline 7 & 0.215 & 0.073 & 0.188 & 0.083 & 0.217 & 0.225 & 0.263 & 0.163 \\
\hline 8 & 0.169 & 0.178 & 0.156 & 0.166 & 0.206 & 0.169 & 0.181 & 0.163 \\
\hline Feedback & $B_{1}$ & $B_{2}$ & $B_{3}$ & $B_{4}$ & $B_{5}$ & $B_{6}$ & $B_{7}$ & $B_{8}$ \\
\hline $\begin{array}{c}b, c \\
c \\
b\end{array}$ & 1 & 2 & 3 & 4 & 5 & 6 & 7 & 8 \\
\hline 1 & 0.437 & -0.273 & 0.028 & 0.115 & 0.000 & 0.209 & 0.332 & 0.118 \\
\hline 2 & 0.849 & 1.433 & 0.009 & -0.133 & -0.029 & -0.311 & -0.223 & -0.026 \\
\hline 3 & -0.337 & -0.073 & 0.998 & -0.097 & -0.073 & 0.332 & 0.010 & 0.059 \\
\hline 4 & 0.435 & -0.059 & 0.005 & 1.075 & 0.134 & -0.269 & 0.086 & 0.014 \\
\hline 5 & -0.114 & 0.417 & -0.012 & 0.081 & 0.973 & 0.031 & -0.079 & -0.043 \\
\hline 6 & -0.254 & -0.259 & 0.014 & -0.012 & 0.006 & 0.938 & 0.098 & 0.074 \\
\hline 7 & -0.112 & 0.035 & -0.020 & 0.055 & 0.013 & 0.238 & 1.002 & 0.000 \\
\hline 8 & 0.163 & -0.186 & -0.002 & -0.084 & -0.023 & -0.119 & -0.146 & 0.944 \\
\hline \multicolumn{9}{|c|}{$\begin{array}{c}\text { Sample Size, } n=420 \\
\text { SSE }=3656 \\
\text { RMSE }=1.043 \\
\text { Average Synaptic Weight }=0.148\end{array}$} \\
\hline
\end{tabular}

\section{Discussion}

This study aimed to assess the determinants of poor households' intention and behavior towards the community forestry in Malaysia. The empirical results support the proposed hypotheses and validate the use of the extended TPB model. The findings reveal a significant, positive, and direct effect of perceived benefit on the ATE along with a significant, positive, and indirect effect on the ITCF among the underprivileged households in Malaysia. In line with previous studies [21,24,27], individuals' perception of the functionality and quality of green behavior can reinforce positive reasons towards the environment leading towards the intention of adopting community forestry.

The findings further show a direct and significant positive influence of EL on the ATE along with an indirect and significant positive effect on the ITCF. The findings concur with the previous studies (cf. [21,26]) that environmental knowledge is the principal factor. It also has an indirect effect on green behavioral intention through the individuals' attitude. In line with Calkins and Thant (2011), this study affirmed that Malaysian low-income households that have adequate environmental information could have positive environmental attitude and make appropriate choices. The use of the ANN analysis enables exploring deeply hidden aspects of ATE with PB and EL. Regarding the two factors, the relative influence of EL is 0.966 of PB. Hence, the ANN suggested that PB might has just as much influence on ATE as EL does, especially the feedback $P_{1}$ and $P_{5}$, where the synaptic weights connected from them are all very positive among all the synaptic weights in the ANN. Such results through ANN, with an RMSE of 0.746 , are considered very accurate for this application, firstly because the truth values are among $\{1,2,3,4,5,6,7\}$; thus, 0.746 is already within the smallest detectable increment/decrement of 1 . The second justifying reason is due to the nature of the data itself: Those are results of people's subjective opinions. As a result, different people are known to have different standards in giving his/her opinion using very subjective descriptions such as "agree" or "disagree". 
$\mathrm{NB}$ and $\mathrm{MO}$ can affect SUN directly, positively, and significantly. In line with TPB and previous studies $[5,18,19]$, it is confirmed that SUN are selected by NBs and MO to comply with the perceived social pressure. The constructs of NB and MO have a significant, positive, and indirect effect on the ITCF. Concurring with the existing literature $[19,24,26,27]$, it can be said that NB and MO, to comply with specific significant referents, are important factors that determine an individual's ITCF through SUN. Through a deep learning algorithm, the resultant ANN further affirms such influence by NB and MO on SUN. Moreover, the relative sensitivity of NB is 0.533 to that of MO. Thus, MO is deemed to have significantly greater overall influence on SUN compared to NB. Such results through ANN, with an RMSE of 0.850 , are considered very accurate for this application, with the same two reasons as mentioned in the ANN analysis on ATE.

For PC, a direct significant positive effect is found on PBC. In line with TPB and previous studies $[5,18,19]$, this finding confirms that control beliefs and control strength form an individual's PBC among the respondents in Malaysia. The findings further reveal a significant positive indirect effect of PC on the ITCF. Supporting the existing literature [19,27], this study reveals that PC can influence an individual's PBC and facilitate the performing community forestry across the sample of the study. The ANN results again affirm the existence of such relationships between PC and PBC highlighted by previous scholars in the area, as it scored an RMSE of 0.794, which is again considered very accurate for this application, with the same two reasons as mentioned in the ANN analysis on ATE.

For attitude, this study found a direct, positive, and significant effect of ATE on the ITCF with an indirect, positive, and significant effect on CFAB. These results are in line with TPB and previous studies $[5,17-20,23,25-27,29]$ that an individual's overall belief towards environment, with the expectation of positive consequences associated with pro-environmental behavior, can lead to adopting the behavior of community forestry. For SUN, the results show a significant positive direct effect on the ITCF with a significant positive and indirect effect on the CFAB. In line with TPB and existing studies $[5,18,23,25-27]$, the results reveal that the views of significant reference groups can influence the head of low-income households' willingness and decision to perform community forestry. It was found that $\mathrm{PBC}$ has a direct and significant positive effect on the ITCF, and an indirect significant positive effect on the CFAB. This finding supports TPB [18] and existing studies [5,25-27] that individuals' positive belief over their capability and perception regarding the availability of necessary resources can enhance their readiness and adoption of community forestry, particularly among the low-income communal groups in Malaysia. Such positive and significant effect on ITCF by ATE, SUN, and PBC, concluded by previous scholars, were likewise all affirmed by the ANN, with more than $90 \%$ of the synaptic weights $w_{a, b}$ being positive. Though their degree of influence of the three factors are deemed quite close in magnitude, ATE is concluded to have the greatest overall influence on ITCF (1.000), followed by SUN (0.923), and then PBC (0.901). Such results through ANN, with an RMSE of 0.781, are again considered very accurate for this application, with the same two reasons as mentioned in the ANN analysis on ATE.

As suspected, there is a direct and significant positive effect of ITCF on CFAB among the respondents. These findings are in line with TPB [18] and related previous studies [26,27] that the willingness to perform community forestry is an immediate and most significant predictor of actual CFAB among the respondents of this study. In line with most existing studies, the overall findings validate the extended TPB model to investigative the determinants of intention and adoption behavior towards community forestry. The results confirm that environment is the strongest determinant of the ITCF. Furthermore, it is the most important factor for the CFAB. The ANN results affirm such relationship between ITCF and CFAB with an RMSE of 1.043.

The new understanding from the results yielded by an ANN, and the accuracy it delivers, thus enable the scholars to explore and predict new direction of research in this field. It also enables the scholars to make conclusions without being affected by the subjectivity of human perceptions, as it is 
now through a deep learning algorithm where all the relationships are identified and all the conclusions are made.

\section{Implication and Conclusions}

Forest resources play an important role for individuals' wellbeing, communities' livelihood, societal development, socioeconomic improvement, and environmental balance [13,15]. Participation and engagement of the local households and community members can ensure sustainable management and the use of natural resources that in turn reduces the environmental degradation and helps to achieve long-term sustainability [16]. This study used an extended TPM model to analyze the effect of selected factors on the intention and adoption behavior towards community forestry among poor families in Malaysia. It is believed that this group forms the major communal group of the rapidly emerging nation. The findings reveal the following: (1) BB and EL have a significant positive effect on the ATE; (2) NB and MO have a significant positive effect on SUN; (3) PC has a significant positive effect on PBC; (4) ATE, SUN, and PBC have a significant positive effect on the ITCF; and (5) the ITCF has a significant positive effect on CFAB. For the mediating effects, the results are as follows: (1) Significant mediating effects of ATE on the relationship of perceived benefit and EL with the ITCF; (2) significant mediating effects of SUN on the association of NB and MO with the ITCF; (3) significant mediating effects of PBC on the link between PC and ITCF; and (4) significant mediating effects of ITCF on the relationships of ATE, SUN, and perceived behavioral control with the CFAB.

This study contributes to the body of knowledge on the determinants of intentional behavior towards community forestry, which received little attention in the existing literature, particularly in the Malaysian context. The empirical results supported the proposed hypotheses and validated the use of the extended TPB model. Hence, TPB is an effective framework for predicting intentions and behavior towards community forestry. This study has effectively expanded TPB by integrating relevant constructs as determinants of the original TPB antecedents. At the same time, this study has enhanced the scope and applicability of TPB by considering the factors of ITCF and CFAB.

This study also contributed by providing a framework for sustainable community forestry, particularly for the local communities cf. $[14,15]$ as well as their perceptions cf. $[5,6]$ and participation in Malaysian context cf. [16]. This study has significant practical and political implications regarding global warming, reducing carbon, and improving socioeconomic conditions of vulnerable, poverty-ridden, low-income households in emerging economies. It is believed that there is the need to formulate continuous sustainable development, policy, and programs to preserve the environment and encourage community-oriented behaviors such as community forestry that can facilitate sustainable exit from poverty, particularly for poor households. Based on our findings, it is recommended that the governments of rapidly growing economies such as Malaysia should focus on raising awareness on pro-environmental behavior, improve NB and MO in favor of pro-environmentalism, and provide training, infrastructure, and other facilities (e.g., loans, subsidies, incentives) to locals in enhancing their intention to perform community forestry. In the effort to improve community forestry adoption, the Malaysian government and socio-developmental organizations could focus on improving the attitude towards the environment by referring to the claim of significant others and develop the ability of local communities to practice pro-environmental activities.

Author Contributions: S.A.F., M.M.M., and N.R.Z. focused on conceptualization, methodology, resources, and writing - original draft preparation. G.S. and Q.S.G. focused on conceptualization, methodology, and ANN analysis. A.A.M. focused on conceptualization, methodology, supervision, and writing-review and editing. All authors have read and agreed to the published version of the manuscript.

Funding: This research received no external funding.

Conflicts of Interest: The authors declare no conflict of interest. 


\section{References}

1. Mohiuddin, M.; Al Mamun, A.; Syed, F.A.; Mehedi Masud, M.; Su, Z. Environmental knowledge, awareness, and business school students' intentions to purchase green vehicles in emerging countries. Sustainability 2018, 10, 1534. [CrossRef]

2. Al Mamun, A.; Nawi, N.B.C.; Ibrahim, M.A.H.B.; Muniady, R. Effect of economic vulnerability on competitive advantages, enterprise performance and sustainability. Soc. Sci. 2018, 7, 54. [CrossRef]

3. Vandenhole, W. De-Growth and sustainable development: Rethinking human rights law and poverty alleviation. Law Dev. Rev. 2018, 11, 647-675. [CrossRef]

4. Jafari, A.; Kaji, H.S.; Azadi, H.; Gebrehiwot, K.; Aghamir, F.; Van Passel, S. Assessing the sustainability of community forest management: A case study from Iran. For. Policy Econ. 2018, 96, 1-8. [CrossRef]

5. Lin, J.C.; Wu, C.S.; Liu, W.Y.; Lee, C.C. Behavioral intentions toward afforestation and carbon reduction by the Taiwanese public. For. Policy Econ. 2012, 14, 119-126. [CrossRef]

6. Wulandari, C.; Inoue, M. The importance of social learning for the development of community based forest management in indonesia: The case of community forestry in Lampung province. Small-Scale For. 2018, 17, 361-376. [CrossRef]

7. Sharma, K. Gender and green governance: The political economy of women's presence within and beyond community forestry. Conserv. Soc. 2014, 2014 12, 107-108. [CrossRef]

8. Njurumana, G.N.; Ginoga, K.; Octavia, D. Sustaining farmers livelihoods through community forestry in Sikka, East Nusa Tenggara, Indonesia. Biodivers. J. Biol. Divers. 2020, 21, 3786-3796. [CrossRef]

9. GFGT (Global Forest Goal and Targets). The United Nations Strategic Plan for Forest 2030; Department of Economic and Social Affairs, United Nations: New York, NY, USA, 2019.

10. Erbaugh, J.T. Responsibilization and social forestry in Indonesia. For. Policy Econ. 2019, 109, 102019. [CrossRef]

11. Rakatama, A.; Pandit, R. Reviewing social forestry schemes in Indonesia: Opportunities and challenges. For. Policy Econ. 2020, 111, 102052. [CrossRef]

12. Ludvig, A.; Wilding, M.; Thorogood, A.; Weiss, G. Social innovation in the Welsh Woodlands: Community based forestry as collective third-sector engagement. For. Policy Econ. 2018, 95, 18-25. [CrossRef]

13. Abdullah, R.M.; Noguchi, T.; Nur, M. Impact of participatory forest management (PFM) on socio-economic development in Bangladesh: A case study in the Madhupur Sal Forest. J. For. Econ. 2007, 53, 46-56.

14. Gill, S.K.; Ross, W.H.; Panya, O. Moving beyond rhetoric: The need for participatory forest management with the Jakun of South-East Pahang, Malaysia. J. Trop. For. Sci. 2009, 21, 123-138.

15. Nelson, J.; Muhammed, N.; Rashid, R.A. Community's forest dependency and its effects towards the forest resources and wildlife abundances in Sarawak, Malaysia. Int. J. Sustain. Dev. World Ecol. 2015, 22, 401-412.

16. Masud, M.M.; Aldakhil, A.M.; Nassani, A.A.; Azam, M.N. Community-based ecotourism management for sustainable development of marine protected areas in Malaysia. Ocean Coast. Manag. 2017, 136, 104-112. [CrossRef]

17. Foundjem-Tita, D.; D’Haese, M.; Speelman, S.; Degrande, A.; Gyau, A.; Van Damme, P.; Tchoundjeu, Z.; VanHuylenbroeck, G. Would strictly enforced forestry regulations affect farmers' stated intentions to plant indigenous fruits trees? Insights from Cameroon. Food Policy 2014, 49, 95-106. [CrossRef]

18. Ajzen, I. The theory of planned behavior. Organ. Behav. Hum. Decis. Process. 1991, 50, 179-211. [CrossRef]

19. Karppinen, H. Forest owners' choice of reforestation method: An application of the theory of planned behavior. For. Policy Econ. 2005, 7, 393-409. [CrossRef]

20. Calkins, P.; Thant, P.P. Sustainable agro-forestry in Myanmar: From intentions to behavior. Environ. Dev. Sustain. 2011, 13, 439-461. [CrossRef]

21. Ahmad, A.N.E.E.S.; Thyagaraj, K.S. Consumer's intention to purchase green brands: The roles of environmental concern, environmental knowledge and self-expressive benefits. Curr. World Environ. 2015, 10, 879-889. [CrossRef]

22. Grob, A. A structural model of environmental attitudes and behaviour. J. Environ. Psychol. 1995, 15, $209-220$. [CrossRef]

23. Ha, H.; Janda, S. Predicting consumer intentions to purchase energy-efficient products. J. Consum. Mark. 2012, 29, 461-469. [CrossRef] 
24. Hartmann, P.; Apaolaza-Ibáñez, V. Consumer attitude and purchase intention toward green energy brands: The roles of psychological benefits and environmental concern. J. Bus. Res. 2012, 65, 1254-1263. [CrossRef]

25. Kaiser, F.G. A moral extension of the theory of planned behavior: Norms and anticipated feelings of regret in conservationism. Personal. Individ. Differ. 2006, 41, 71-81. [CrossRef]

26. Maichum, K.; Parichatnon, S.; Peng, K.C. Application of the extended theory of planned behavior model to investigate purchase intention of green products among Thai consumers. Sustainability 2016, 8, 1077. [CrossRef]

27. Wu, S.; Chen, J. A Model of green consumption behavior constructed by the theory of planned behavior. Int. J. Mark. Stud. 2014, 6, 119-132. [CrossRef]

28. Griskevicius, V.; Tybur, J.M.; Bergh, B.V.D. Going green to be seen: Status, reputation, and conspicuous conservation. J. Personal. Soc. Psychol. 2010, 98, 392-404. [CrossRef]

29. López-Mosquera, N.; Lera-López, F.; Sánchez, M. Key factors to explain recycling, car use and environmentally responsible purchase behaviors: A comparative perspective. Resour. Conserv. Recycl. 2015, 99, $29-39$. [CrossRef]

30. Prime Minister's Department. Government Transformation Programme Annual Report. Available online: https://www.pemandu.gov.my/assets/publications/annual-reports/GTP_2011_EN.pdf (accessed on 12 December 2017).

31. Faul, F.; Erdfelder, E.; Buchner, A.; Lang, A.G. Statistical power analyses using G* Power 3.1: Tests for correlation and regression analyses. Behav. Res. Methods 2009, 41, 1149-1160. [CrossRef]

32. Wolf, E.J.; Harrington, K.M.; Clark, S.L.; Miller, M.W. Sample size requirements for structural equation models: An evaluation of power, bias, and solution propriety. Educ. Psychol. Meas. 2013, 73, 913-934. [CrossRef]

33. Reinartz, W.; Haenlein, M.; Henseler, J. An empirical comparison of the efficacy of covariance-based and variance-based SEM. Int. J. Res. Mark. 2009, 26, 332-344. [CrossRef]

34. Mostafa, M. Antecedents of Egyptian Consumers' Green Purchase Intentions. J. Int. Consum. Mark. 2006, 19, 97-126. [CrossRef]

35. Chen, K.; Deng, T. Research on the Green Purchase Intentions from the Perspective of Product Knowledge. Sustainability 2016, 8, 943. [CrossRef]

36. Walton, T.; Austin, D. Pro-environmental behavior in an urban social structural context. Sociol. Spectr. Mid-South Sociol. Assoc. 2011, 31, 260-287. [CrossRef]

37. Sánchez, M.; López-Mosquera, N.; Lera-López, F. Improving pro-environmental behaviours in Spain. The role of attitudes and sociodemographic and political factors. J. Environ. Policy Plan. 2016, 18, 47-66. [CrossRef]

38. Osman, A.; Isa, F.; Othman, S.; Jaganathan, M. Attitude towards recycling among business undergraduate students in Malaysia. Am.-Eurasian J. Sustain. Agric. 2014, 8, 6-12.

39. Podsakoff, P.M.; MacKenzie, S.B.; Lee, J.Y.; Podsakoff, N.P. Common method biases in behavioral research: A critical review of the literature and recommended remedies. J. Appl. Psychol. 2003, 88, 879-903. [CrossRef]

40. Bagozzi, R.P.; Yi, Y.; Phillips, L.W. Assessing construct validity in organizational research. Adm. Sci. Q. 1991, 36, 421-458. [CrossRef]

41. Shmueli, G.; Sarstedt, M.; Hair, J.F.; Cheah, J.-H.; Ting, H.; Vaithilingam, S.; Ringle, C.M. Predictive model assessment in PLS-SEM: Guidelines for using PLSpredict. Eur. J. Mark. 2019, 53, 2322-2347. [CrossRef]

42. Hair, J.F.; Risher, J.J.; Sarstedt, M.; Ringle, C.M. When to use and how to report the results of PLS-SEM. Eur. Bus. Rev. 2019, 31, 2-24. [CrossRef]

43. Chong, A.Y.L. A two-staged SEM-neural network approach for understanding and predicting the determinants of m-commerce adoption. Expert Syst. Appl. 2013, 40, 1240-1247. [CrossRef]

44. Diamantopoulos, A.; Siguaw, J.A. Formative versus reflective indicators in organizational measure development: A comparison and empirical illustration. Br. J. Manag. 2006, 17, 263-282. [CrossRef]

(C) 2020 by the authors. Licensee MDPI, Basel, Switzerland. This article is an open access article distributed under the terms and conditions of the Creative Commons Attribution (CC BY) license (http://creativecommons.org/licenses/by/4.0/). 